\title{
Stratosphere-troposphere exchange: Chemical sensitivity to mixing
}

\author{
J. Gavin Esler, ${ }^{1}$ David G. H. Tan, ${ }^{2}$ and Peter H. Haynes \\ Department of Applied Mathematics and Theoretical Physics, Centre for Atmospheric Science \\ University of Cambridge, Cambridge, England \\ Mathew J. Evans, ${ }^{3}$ Kathy S. Law, Paul-Henri Plantevin, and John A. Pyle \\ Department of Chemistry, Centre for Atmospheric Science, University of Cambridge, Cambridge \\ England
}

\begin{abstract}
We present examples of how chemical evolution can exhibit sensitivity to mixing arising from stratosphere-troposphere exchange. A chemical transport model is used to survey the chemical contrasts on isentropic surfaces that intersect the tropopause. Significant cross-tropopause gradients in both ozone and water vapor are shown to exist between 300 and $340 \mathrm{~K}$. Back trajectories are used to confirm that air parcels with widely varying chemical properties are rapidly brought together in a typical quasi-isentropic stratosphere-troposphere exchange event. A two-box model is used to investigate the chemical evolution of stratospheric and tropospheric air parcels and to determine the effect of mixing between them. Mixing of stratospheric ozone and tropospheric water vapor is shown to lead to enhanced hydroxyl $(\mathrm{OH})$ radical concentrations compared with background tropospheric and stratospheric values. The oxidation of $\mathrm{CO}$, methane, and higher hydrocarbons is correspondingly increased, and $\mathrm{NO}_{x}$ is also lost more rapidly with faster mixing. Also, in low $\mathrm{NO}_{x}$ conditions, the rate of $\mathrm{O}_{3}$ loss is found to increase with faster mixing. The consequences of this anomalous chemistry for chemical transport in stratosphere-troposphere exchange events are discussed. It is also noted that if $\mathrm{NO}_{x}$ levels in either parcel are very high initially, mixing of $\mathrm{NO}_{x}$ can become more important than $\mathrm{O}_{3}$ or $\mathrm{H}_{2} \mathrm{O}$ in determining $\mathrm{OH}$ levels.
\end{abstract}

\section{Introduction}

Exchange of trace gases between the lowermost stratosphere and troposphere has always been regarded as a particularly important aspect of chemical transport in the atmosphere [e.g., Holton et al., 1995]. The complicated nature of the mixing processes involved in middle-latitude stratosphere-troposphere exchange raises many intriguing questions about their overall effect on atmospheric chemical distributions. There are several compelling reasons as to why sensitivity to details of mixing is likely to be important, and the focus

\footnotetext{
${ }^{1}$ Now at Department of Mathematics, University College, London, England.

${ }^{2}$ Now at The Hadley Centre, Meteorological Office, Bracknell, England.

${ }^{3}$ Now at Department of Atmospheric Sciences, Harvard University, Cambridge, Massachusetts.
}

Copyright 2001 by the American Geophysical Union.

Paper number 2000JD900405.

0148-0227/01/2000JD900405\$09.00 of this paper is this relatively poorly understood aspect of stratosphere-troposphere exchange.

For a chemical system to admit the possibility of sensitivity to mixing, two generic features are necessary. The first is the existence of two regions with significant contrasts in their respective chemical composition and the second is a transport mechanism that leads to irreversible exchange and hence chemical mixing between air masses originating in the two regions. The situation considered in this paper is precisely of this type. The stratosphere and troposphere have significant contrasts in ozone (high in the former and low in the latter) and in water vapor (low in the former and high in the latter). Furthermore, there are frequent exchange events in which, for example, intrusions of stratospheric air entering the troposphere in tropopause folds [e.g., $A p$ penzeller et al., 1996] or alternatively tropospheric intrusions enter the stratosphere.

Most such exchange events are thought to be initiated by quasi-isentropic deformation of the tropopause. The near-isentropic nature of the trajectories involved in such events clearly restricts the range of contrast- 
ing chemical concentrations that can be rapidly brought into contact to those on nearby isentropic surfaces (see section 2 of this paper). This near-isentropic restriction may in turn constrain the extent of any anomalous chemistry that may arise through mixing between stratospheric and tropospheric air. However, one possible exception to this is the erosion of the lower stratosphere by convective mixing in the case of cloud tops penetrating across the tropopause [Ancellet et al., 1994]. Parcel trajectories in convective clouds are not subject to such isentropic restrictions, so this mechanism can potentially bring together, and mix rapidly, stratospheric air near the tropopause with air originating in the lower troposphere. However, the global importance of this mechanism for stratosphere-troposphere exchange has not yet been fully assessed.

Sensitivity to mixing is likely to be greatest when there is a wide range of chemical timescales and the mixing timescale falls within this range. Stratospheretroposphere exchange processes have these properties: for example, the quasi-isentropic transport processes mentioned above are adiabatic motions on timescales of days and the associated mixing has dilution timescales of a few days [McIntyre, 1992; Holton et al., 1995; Mahlman, 1997]. Chemical timescales range upwards from a few minutes or less for short-lived radicals such as the hydroxyl radical $\mathrm{OH}$, to days, weeks or longer for reservoir species, such as $\mathrm{O}_{3}$ and $\mathrm{CO}$. At fixed rates of photolysis, $\mathrm{OH}$ concentrations are largely determined by the concentrations of longer lived species, so mixing thus offers one mechanism for significant adjustment to the $\mathrm{OH}$ concentrations. Given the central role of $\mathrm{OH}$ in tropospheric chemistry [e.g., Ehhalt, 1998], such adjustment is likely to have significant implications for the chemistry of longer lived species, such as $\mathrm{O}_{3}$ and hydrocarbons, and thus an impact on the chemistry climate system.

The regime where the mixing timescale falls within the range of chemical timescales is also problematical for numerical modeling. There are two extremes here: box models typically describe the evolution of isolated air parcels, often following a trajectory through space but without mixing between different boxes or with the surrounding background. Thus the mixing timescale in box models is essentially infinite rather than falling within the range of chemical timescales. One notable modeling exception is the work of Wild et al. [1996] who did consider mixing in a box model study of polluted marine boundary layer air. They noted that the effects of mixing could be more important than photochemical processes and emphasized the need for more detailed investigations of mixing. At the other extreme, grid-based models effectively mix too quickly whenever they cease to resolve small-scale tracer features, prematurely homogenizing them at the model grid scale [e.g., Thuburn and Tan, 1997; Tan et al., 1998, and references therein].
In this paper we use a two-box chemical model, augmented by a simple volume exchange model of mixing, to illustrate the sensitivity of chemical evolution when relatively dry, ozone-rich stratospheric air is mixed with moist, ozone-poor tropospheric air. In section 2 we discuss in more detail the chemical contrasts between stratospheric and tropospheric air, with an emphasis on the range of concentrations of $\mathrm{O}_{3}$ and $\mathrm{H}_{2} \mathrm{O}$ that can be brought together by stirring and mixing on each isentropic surface. Detailed forward and backward threedimensional trajectory calculations are then used to illustrate the stirring of stratospheric and tropospheric air as a cutoff low is ejected from the stratosphere. The synoptic-scale event in question took place around the March 5, 1995, and was studied as part of the European Union Transport of Ozone and StratosphereTroposphere Exchange-B (TOASTE-B) project [Ancellet et al., 1996]. Trajectories originating in the stratosphere and troposphere are shown to converge around the cut-off low and, in some cases, remain together as the low is mixed into the troposphere. Such trajectories are selected as suitable for our idealized mixing experiments. In section 3 the box modeling experiments are described. The initial chemical concentrations are taken from the results of a three-dimensional, global, Eulerian chemical transport model experiment, run at relatively high resolution over the same period in March 1995. The box model is run along the stratospheric and tropospheric trajectories separately without mixing until the trajectories converge, after which time mixing proceeds at a fixed rate between the two boxes along a single trajectory. The results, and their sensitivity to different initial chemical concentrations and physical conditions, are discussed in section 4. Finally, in section 5 we present our conclusions.

\section{Stirring of Stratospheric and Tropospheric Air}

To gain some insight into the range in chemical contrasts that can be brought together by (near) isentropic mixing, and to motivate the idealized box-modeling experiments that follow, we have surveyed the range of cross-tropopause chemical contrasts in the TOMCAT chemical transport model [Stockwell and Chipperfield, 1999; Law et al., 1998] and made a detailed trajectorybased study of the stirring of a stratospheric intrusion into the troposphere.

Quasi-isentropic mixing events in the region of the extratropical tropopause have recently been categorized by Peters and Waugh [1996], based on the earlier work of Thorncroft et al. [1993]. They presented four different paradigms of baroclinic wave breaking events that can lead to irreversible transport between the stratosphere and troposphere (or vice versa), which they label LC1, LC2, P1, and P2. In an LC1-type event, a filament of stratospheric air is advected into the troposphere, 
thinned out, and eventually mixed [Appenzeller and Dovies, 1992; Thorncroft et al., 1993], although roll-up of the filament (or streamer) has also been observed [Appenzeller et al., 1996]. An LC2 event involves the formation of a cutoff cyclonic vortex of stratospheric air in the troposphere, which either returns to the stratosphere after a few days [Thorncroft et al., 1993] or is stirred and mixed into the troposphere [Price and Vaughan, 1993; Gouget et al., 2000]. A P1 event is a mirror image of an LC1-event, with a filament of tropospheric air entering the stratosphere, and in a $\mathrm{P} 2$ event a cutoff anticyclonic vortex of tropospheric air enters the stratosphere, where it either remains for a few days before returning to the troposphere [Peters and Waugh, 1996] or is stirred and mixed into the background stratospheric air [Voughan and Timmis, 1998].

An important issue is how the type and frequency of these events varies in the vertical. Several authors [Chen, 1995; Eluskiewicz, 1996; Bithell and Gray, 1997; Haynes and Shuckburgh, 2000] have shown that the barrier to transport represented by the tropopause becomes more robust at higher levels $(340-380 \mathrm{~K})$. At these levels, where the tropopause is located in the subtropics, cross-tropopause mixing was found to be confined to a narrow region around the tropopause itself, and was also subject to a seasonal cycle with stronger exchange in the summer season. At lower levels (290-330 K) vigorous exchange takes place in all seasons, as synopticscale waves break continuously.

\subsection{Chemical Contrasts Across the Tropopause}

Figure 1 shows $\mathrm{H}_{2} \mathrm{O}$ and $\mathrm{O}_{3}$ taken from the TOMCAT model on March 5, 1995, with respect to equivalent latitude [e.g., Butchart and Remsberg, 1986] and potential temperature (see caption for details). The tropopause is indicated schematically by the $100 \mathrm{ppbv}$ $\mathrm{O}_{3}$ contour. The advantage of presenting the data in this way is that one can easily see the range of $\mathrm{H}_{2} \mathrm{O}$ and $\mathrm{O}_{3}$ mixing ratios of the different air masses that can be brought together by isentropic mixing across the tropopause. The direction of isentropic mixing is illustrated by the two-way arrows. The use of equivalent latitude also ensures that these plots are largely independent of instantaneous meteorological conditions. It is clear that, as potential temperature increases, the contrast in $\mathrm{O}_{3}$ mixing ratios across the tropopause increases, but the contrast in water vapor decreases. This is due to low temperatures in the tropical upper troposphere reducing the saturation mixing ratio. At higher levels there are also very large contrast in $\mathrm{O}_{3}$ levels within the stratosphere itself. It appears unlikely that very high values of $\mathrm{O}_{3}(>1000 \mathrm{ppbv})$ are often transported into the troposphere by the weaker isentropic stirring at these levels.

Other species also have significant isentropic gradients across the tropopause in TOMCAT. Above $320 \mathrm{~K}$,
$\mathrm{NO}_{x}$ concentrations are significantly higher in the stratosphere (0.1-0.5 ppbv) than the unpolluted troposphere $(<0.1$ ppbv). Below $320 \mathrm{~K}$ the contrast across the tropopause is less significant but, particularly on those isentropic surfaces which intersect the ground (300 K and below), plumes of very high $\mathrm{NO}_{x}$ that originate in the boundary layer exist intermittently in the troposphere [Brunner et al., 1998]. Cross-tropopause gradients in carbon monoxide are relatively weak, with concentrations lower in the stratosphere than the troposphere, and concentrations decreasing with increasing potential temperature.

\subsection{A Case Study: TOASTE-B in March 1995}

In order to gain some insight into the stirring of a synoptic-scale air mass during a particular stratospheretroposphere exchange (STE) event, an ensemble of threedimensional forwards and backwards trajectories was initialized at the location of a typical stratospheric intrusion into the troposphere (see Ancellet et al. [1996] for a description of the event in question). The $31 \times 19$ trajectories were initialized on March 5, 1995, on the $300 \mathrm{~K}$ isentrope in a region over central southern Europe marked by the black box in Plate 1c, and were advected forwards and backwards [Methven, 1997] by European Centre for Medium-Range Weather Forecasts (ECMWF) analyzed winds at T106 resolution (equivalent to a grid resolution of approximately $1.25^{\circ} \times$ $1.25^{\circ}$ ), for 5 days. Plates $1 \mathrm{a}$ and $1 \mathrm{~b}$, and $1 \mathrm{f}$ and $1 \mathrm{~g}$, show the calculated parcel positions superimposed on contour plots of potential vorticity (PV hereafter) on the $300 \mathrm{~K}$ isentropic surface, on February 28 and March 2, 7 and 10 respectively. The parcels are colored according to their PV on February 28, with red parcels (defined as having stratospheric origin) denoting values greater than 3 PVU (1 potential vorticity unit (PVU) $=10^{-6} \mathrm{~K} \mathrm{~m}^{2} \mathrm{~kg}^{-1} \mathrm{~s}^{-1}$ ), yellow parcels (tropopause origin) 1-3 PVU and black parcels (tropospheric origin) less than 1 PVU. Note that as parcels do not remain exactly on the $300 \mathrm{~K}$ surface, the PV of each parcel does not correspond exactly with the PV field contoured in Plate 1a. The back trajectories are reasonably close to being isentropic, with $80 \%$ originating between $286.5 \mathrm{~K}$ and $310.2 \mathrm{~K}$ on the February 28.

The origin of the air in the intrusion, as defined by its PV 5 days previously, can be seen in Plate 1d. In this panel we are effectively using the reverse-domainfilling technique [Sutton et al., 1994] to create a highresolution picture of the intrusion. The panel shows an enlargement of the region of initialization shown in Plate 1c. Significantly, this picture shows that most of the air in the vortex at this level has a clear stratospheric signature, with only a thin layer around its edge containing air of tropopause origin. This contrasts with the impression given by certain contour advection calculations [e.g., Appenzeller et al., 1996] which often suggest that large proportions of the air in some intrusions 


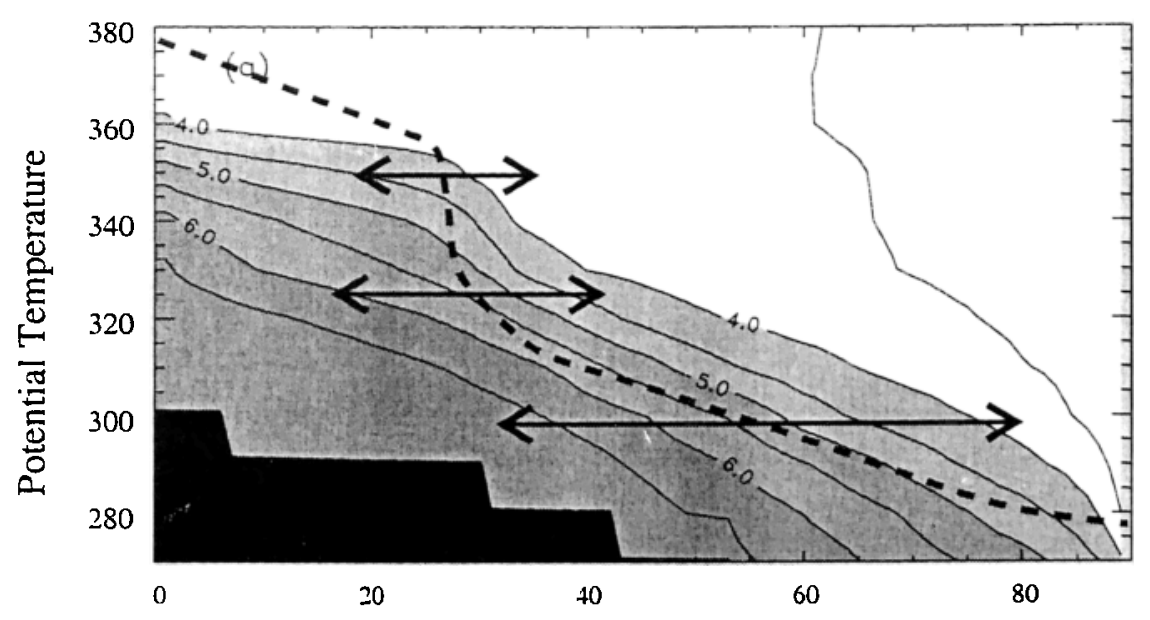

Equivalent Latitude

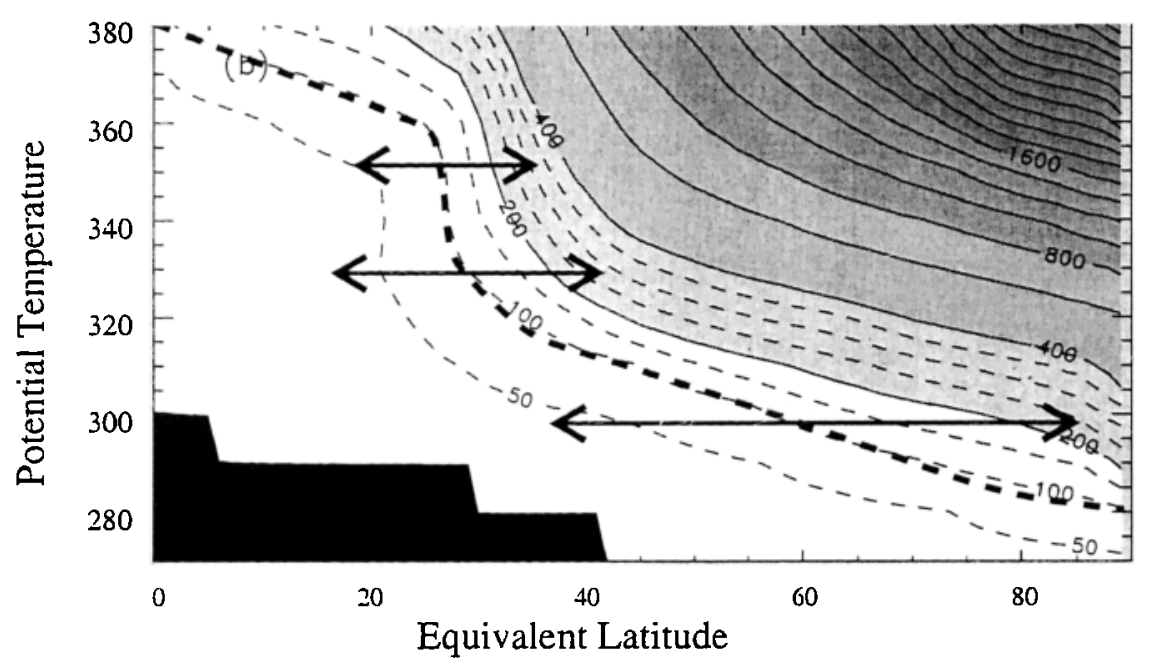

Figure 1. Contour plots of (top) $\log _{10}$ water vapor mixing ratio and (bottom) ozone mixing ratio in TOMCAT (both in ppbv). A schematic tropopause is marked at $100 \mathrm{ppbv}$ ozone, and two-way arrows show the air masses brought together by cross-tropopause isentropic mixing. Contour intervals are 0.5 for the plot of $\log _{10}\left[\mathrm{H}_{2} \mathrm{O}\right]\left(\mathrm{H}_{2} \mathrm{O}\right.$ mixing ratios are in ppbv; note that TOMCAT $\mathrm{H}_{2} \mathrm{O}$ is interpolated from ECMWF analyses) and $50 \mathrm{ppbv}$ (dashed curves) / 200 ppbv (solid curves) in the case of $\mathrm{O}_{3}$. Data are plotted against equivalent latitude and potential temperature. (Equivalent latitude on a given isentrope is defined in this case as a function of $\mathrm{O}_{3}$ (or $\mathrm{H}_{2} \mathrm{O}$ ) concentration. For a given $\mathrm{O}_{3}\left(\mathrm{H}_{2} \mathrm{O}\right)$ concentration it is defined to be equal to that latitude which encloses an area equal to the area of fluid on the surface with a greater $\mathrm{O}_{3}$ (lower $\mathrm{H}_{2} \mathrm{O}$ ) concentration. Black regions indicate areas where the isentropic surface has intersected the ground.)

originate from the tropopause region, rather than the interior of the stratosphere.

The eventual fate of the intrusion is illustrated in Plates $1 \mathrm{e}-1 \mathrm{~g}$. It is quickly detached from the stratosphere on this level, and 2 days later on March 7, most of it remains as a coherent vortex, with a long filament attached to its northernmost edge. By March 10 the filament has been mixed across the troposphere, with some parcels even reentering the stratosphere. The rest of the vortex has been stretched into two filaments, marked by the two boxes in Plate 1g. The final positions of the air parcels in the cutoff low are shown in Plate 1e (dark blue parcels end up in the filament within the left box, green parcels end up in the right box).

It is clear from these forward trajectory calculations that a wide range of timescales are relevant to the mixdown of the fluid in typical stratosphere-troposphere exchange events such as this one. Over just 2 days, strong stretching of the upper section of the intrusion produces a horizontal scale less than the initial parcel separation distance $(\approx 15 \mathrm{~km})$, visible in Plate if (March 7). By contrast, over 5 days much weaker stretching has been acting on the larger of the two filaments evident in Plate $1 \mathrm{~g}$ (March 10). In places the grouping of the parcels suggest that this filament still 
(A)

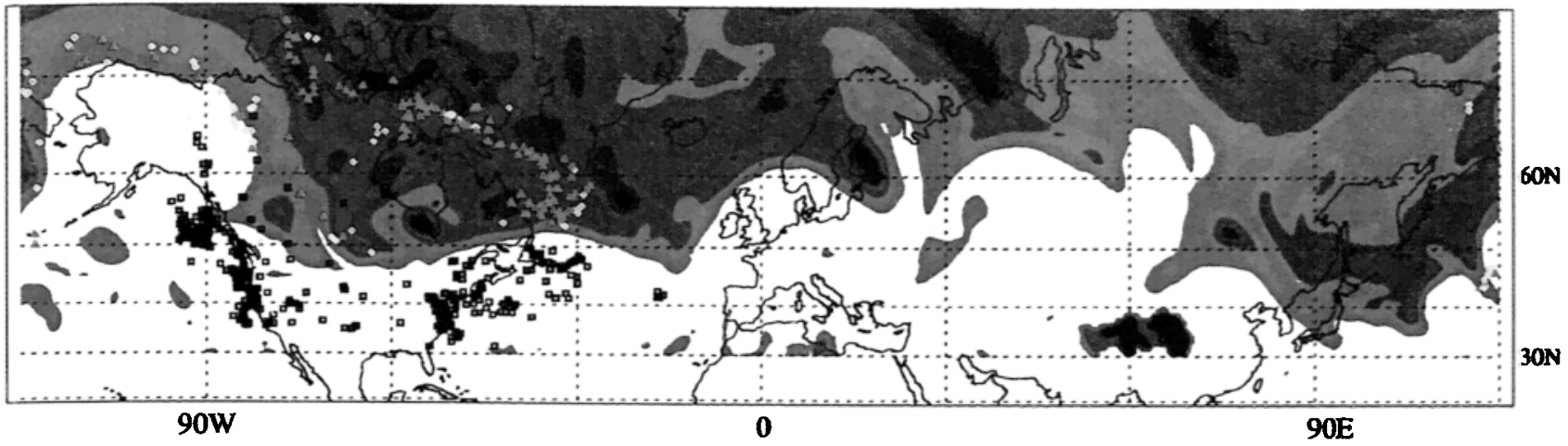

(B) ECMWF PV 300K $02039500 Z$

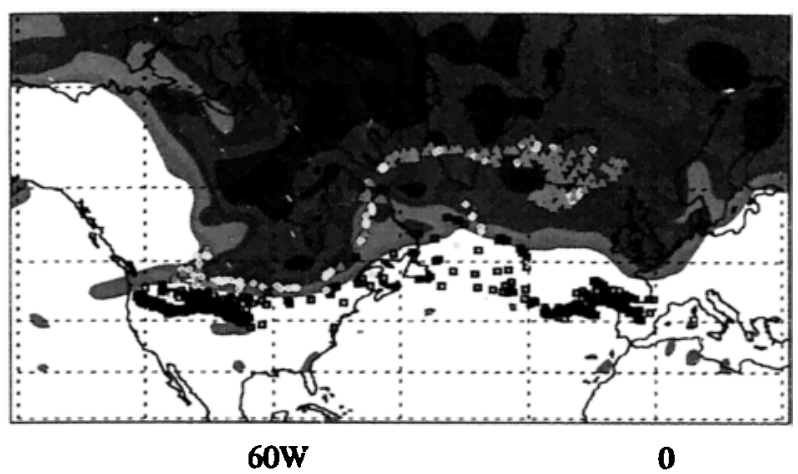

(D) Original PV

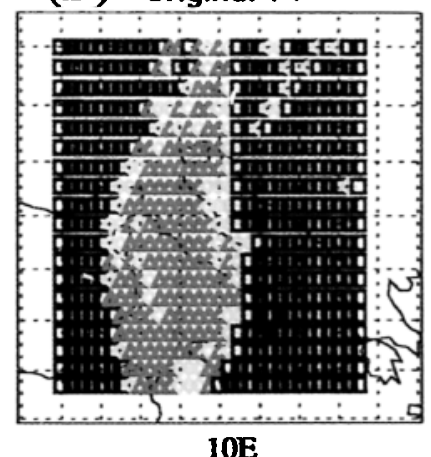

(F)

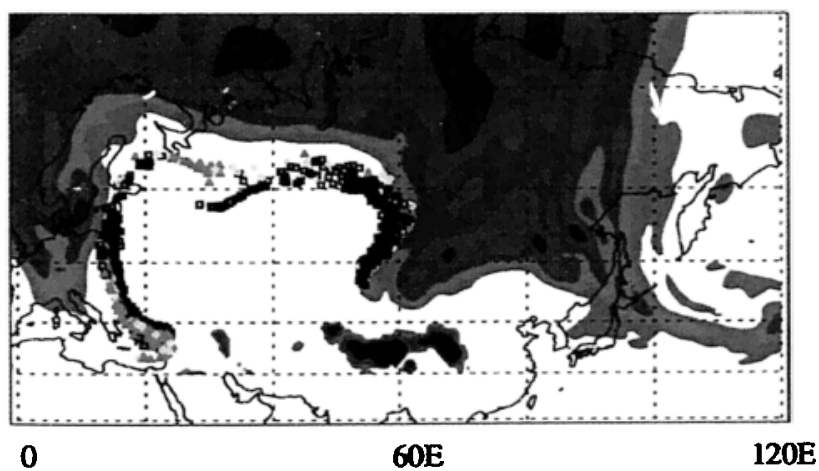

(C) ECMWF PV 300K $05039500 Z$

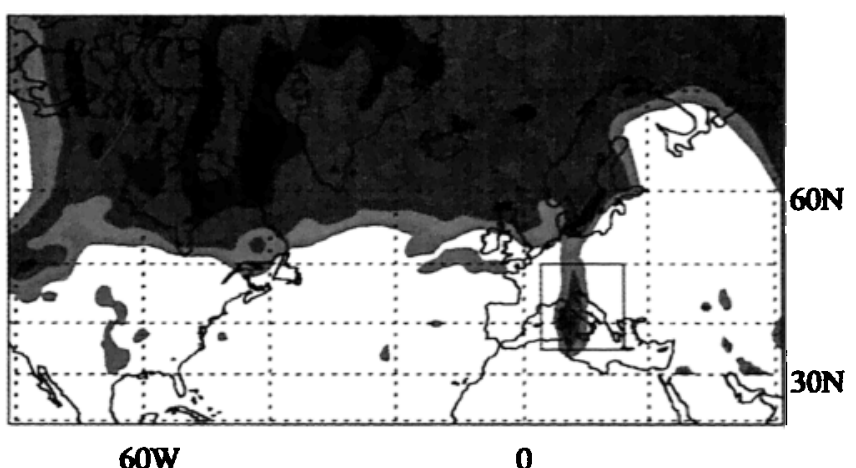

(E) Final Positions

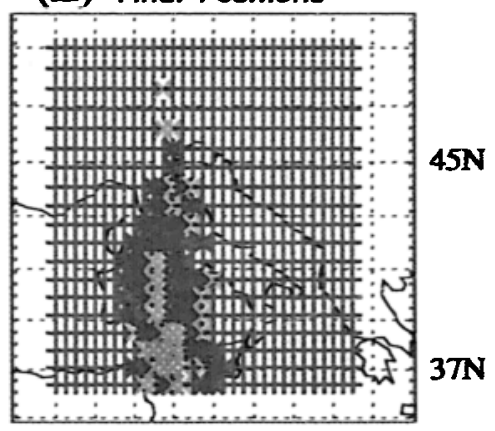

$10 \mathrm{E}$

(G)

ECMWF PV 300K $10039500 Z$

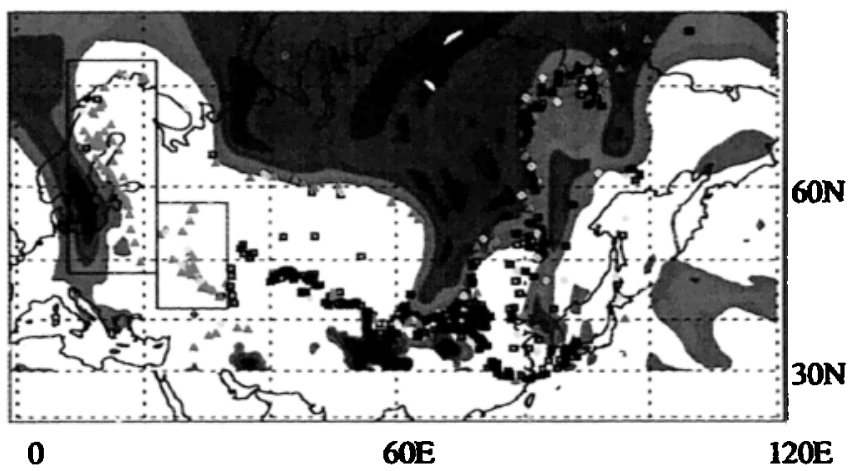

Plate 1. Contour plots of PV on the $300 \mathrm{~K}$ isentrope on (a) February 28, 1995, (b) March 2, (c) March 5, (f) March 7, (g) March 10. Color intervals are at every 1 PVU. Superimposed are trajectory positions at these times. Red parcels indicate initial PV on February $28>3$ PVU, yellow parcels between 1 and 3 PVU, and black < 1 PVU. (d) A close-up of the box in Plate 1c showing the initial PV (on February 28) of the parcels in the stratospheric intrusion on March 5 (the time when the trajectories were started). (e) Related to final parcel positions on March 10, see text. 

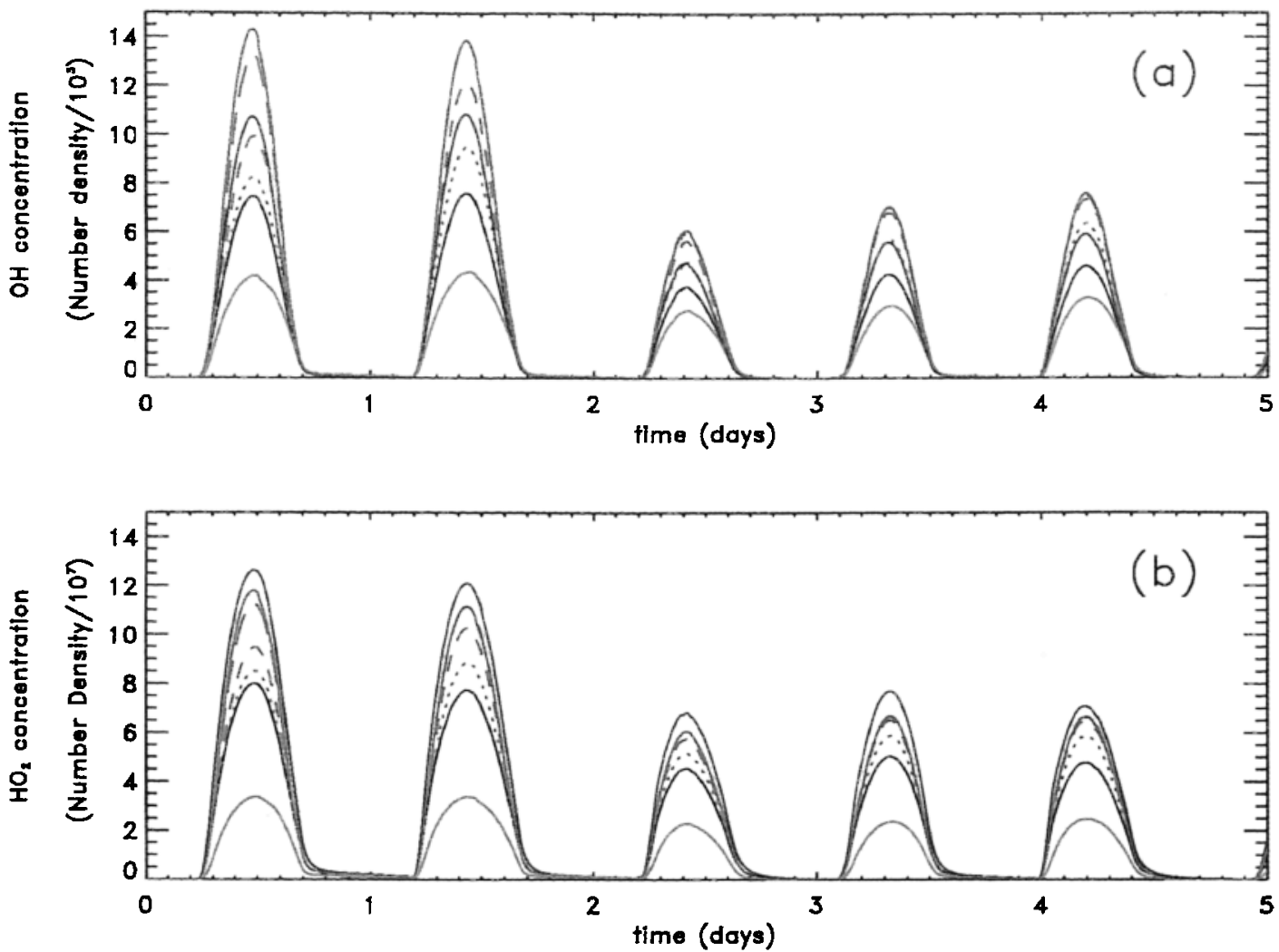

Plate 2. Plots showing (a) $\mathrm{OH}$ and (b) $\mathrm{HO}_{2}$ concentrations along the realistic trajectory in the two-box model experiments: blue curve, Box T; red curve, Box S; green curve, Box M; black curve, average Box $\mathrm{T} / \mathrm{Box} \mathrm{S}$. Broken green curves indicate the results when mixing takes place at a finite rate between Box T and Box S. (Results shown are the average between the two boxes.) Long dashes denote $R=1$ day $^{-1}$, short dashes $R=0.2$ day $^{-1}$, and dots $R=0.05$ day $^{-1}$.) Note that time is measured from $00 \mathrm{Z}$ on March 5 (i.e., it is time at $0^{\circ}$ longitude).
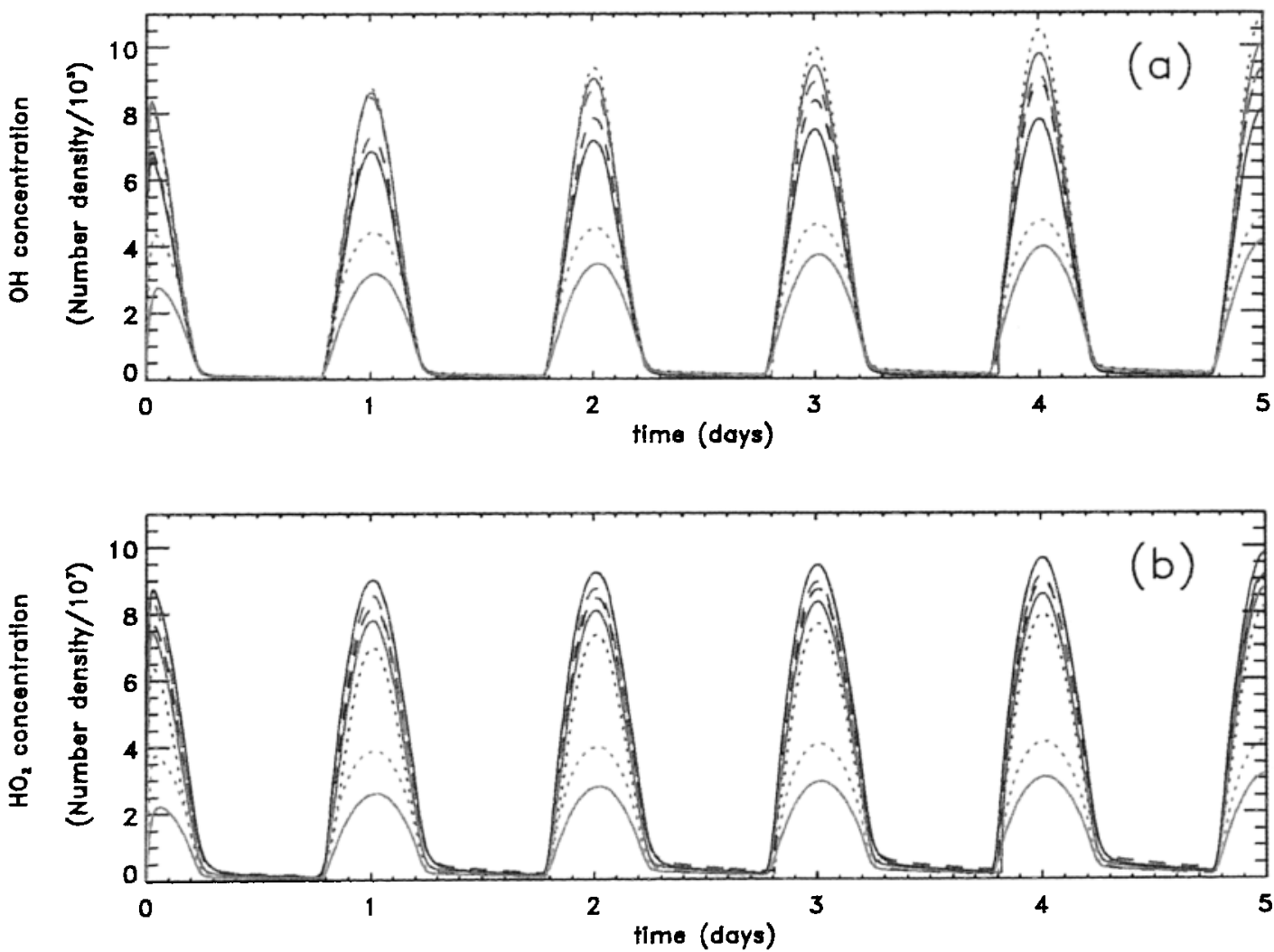

Plate 3. As Plate 2, but showing concentrations calculated along the idealized trajectory. In this case; blue solid curve, Box T; red solid curve, Box S; green solid curve, Box M; dashed green curve, Box A; dotted green curve, Box B; dashed blue curve, Box C; dotted red curve, Box D. Time in this case is measured from $12 \mathrm{Z}$ on March 5 . Note that in this case the box position is fixed at $0^{\circ}$ longitude. 
has a horizontal scale of around $50-100 \mathrm{~km}$. Based on calculations for the stratosphere, and assuming a diffusivity of $10^{-2} \mathrm{~m}^{2} \mathrm{~s}^{-1}$, the horizontal length scale at which filaments are likely to have a vertical length scale sufficiently small for diffusion to act is around $13 \mathrm{~km}$ [Haynes and Anglade, 1997]. The equivalent calculation for the upper troposphere-lower stratosphere region hàs not yet been attempted.

\section{Description of Experiments}

\subsection{Chemical Box Model With Mixing}

We adapt the approach of Tan et al. [1998] by employing a reaction scheme suitable for the lower stratosphere and upper troposphere. The photochemistry scheme consists of reactions of ozone and oxides of nitrogen together with methane and hydrocarbon oxidation schemes [Wild et al., 1996; Evans et al., 2000]. No explicit halogen chemistry is included. The numerical time step is set to 5 minutes.

The volume-exchange model of mixing is as follows. We consider two boxes, A and B say, to represent air parcels whose volumes are in the ratio

$$
\kappa=\operatorname{volume}(\mathrm{B}) / \operatorname{volume}(\mathrm{A}) .
$$

Both boxes are assumed to be well mixed, and we denote by $\chi^{\mathrm{A}}(t)$ and $\chi^{\mathrm{B}}(t)$ the mixing ratio at time $t$ in boxes $A$ and $B$, respectively, of a chemical species $\chi$. An equal volume is exchanged between boxes $A$ and $\mathrm{B}$ at a constant rate $R$, where by convention $R$ is taken to have units of fraction of box B per unit time. Within each modified box the mixing ratio of each chemical species is assumed to achieve spatial homogeneity on a timescale much shorter than the photochemical timescales, so that each box remains well mixed. The mixing ratios $\chi^{\mathrm{A}}(t)$ and $\chi^{\mathrm{B}}(t)$ therefore evolve according to

$$
\begin{aligned}
& \frac{d \chi^{\mathrm{A}}}{d t}=\sigma^{\mathrm{A}}-\kappa R\left(\chi^{\mathrm{A}}-\chi^{\mathrm{B}}\right), \\
& \frac{d \chi^{\mathrm{B}}}{d t}=\sigma^{\mathrm{B}}+R\left(\chi^{\mathrm{A}}-\chi^{\mathrm{B}}\right),
\end{aligned}
$$

where $\sigma(t)$ denotes the net photochemical source of $\chi$ per unit volume (the production minus the loss) and the superscripts $A$ and $B$ refer to the box being considered. A passive tracer (one for which $\sigma^{\mathrm{A}}=\sigma^{\mathrm{B}}=0$ ) homogenizes with an $e$-folding dilution timescale of $((1+\kappa) R)^{-1}$

\subsection{Trajectory Selection and Chemical Initialization}

Figure 2 shows two 10-day trajectories selected from the ensemble described above. Of these, the trajectory marked by squares starts in the stratosphere and that marked by diamonds in the troposphere. The two trajectories clearly come together, in both the horizontal and in the vertical, on the edge of the stratospheric intrusion around $00 \mathrm{Z}$ on March 5, 1995 (when they are separated by about $15 \mathrm{~km}$ ), and remain close together for the next 5 days. This makes them ideal candidates for a trajectory-based mixing experiment.

The chemical boxes are initialized with TOMCAT concentrations at the locations of these trajectories on February 28, 1995. Detailed comparison of results from
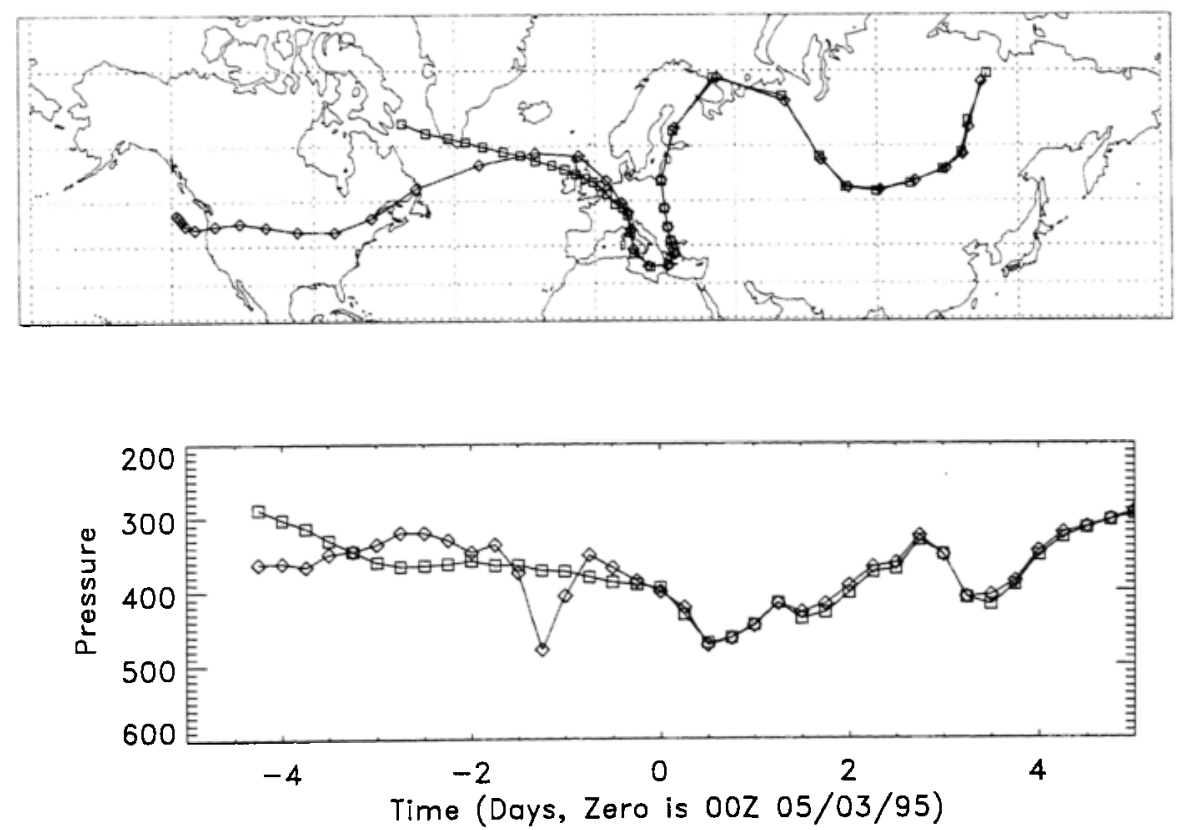

Figure 2. Showing the paths of two trajectories, one beginning in the troposphere (diamonds) and the other the stratosphere (squares) that converge in the intrusion on March 5 and remain together. 
TOMCAT calculations and in-flight observations have been made [Law et al., 1998, 2000] and the discussion in these papers cast light on many of the possible problems associated with using TOMCAT and other chemical transport model results as a proxy for observations. These problems include the "smearing" of tropopause gradients due to diffusion associated with the model advection scheme. It is worth noting that for our study we have used a high-resolution version of TOMCAT and have chosen trajectories originating from well within the troposphere and stratosphere to minimize this problem.

The TOMCAT experiment was spun-up for several months at T21 resolution (corresponding to a grid of approximately $5.5^{\circ} \times 5.5^{\circ}$ ), then reinitialized at $\mathrm{T} 42$ $\left(2.5^{\circ} \times 2.5^{\circ}\right)$ resolution on February 22, and run forward to March 10. Figure 3 shows TOMCAT ozone and $\mathrm{H}_{2} \mathrm{O}$ interpolated to the $300 \mathrm{~K}$ surface for February 28 , along with the origin of the stratospheric (triangle) and tropospheric (square) trajectories. It is clear that despite the much lower resolution of the TOMCAT experiment compared to the ECMWF analyzed winds (T42 as compared with $\mathrm{T} 106$ ), the ozone and $\mathrm{H}_{2} \mathrm{O}$ fields in the chemical transport model are well correlated with the ECMWF PV (Plate 1a). The tropopause, distinguished by strong $\mathrm{O}_{3}$ and $\mathrm{H}_{2} \mathrm{O}$ gradients, is visible in both fields and is also well aligned with the strong gradients in PV in the ECMWF analysis (although the latter is considerably sharper due to lower numerical diffusion in the high resolution analysis). Table 1 shows the initial chemical concentrations of the parcels at the beginning of their trajectories on February 28, 1995 (see figures in parentheses). Comparison with Figure 3 reveals that the stratospheric and tropospheric $\mathrm{H}_{2} \mathrm{O}$ and $\mathrm{O}_{3}$ concentrations chosen are quite typical of the concentrations at the $300 \mathrm{~K}$ isentropic level.

\section{Box-Modeling Results}

\subsection{Sensitivity to Mixing Rate Along a Realistic Trajectory}

The two boxes were integrated along the trajectories shown in Figure 2 from 212 on February 28 to $00 \mathrm{Z}$ on March 5 without mixing, during which time the chemical composition changed as shown in Table 1 (see columns for boxes $\mathrm{T}$ and S). From $00 \mathrm{Z}$ on March 5 to $00 \mathrm{Z}$ on March 10, the two boxes were then integrated along the same trajectory, with a range of mixing rates $R$ given by $0,0.05$ day $^{-1}, 0.2$ day $^{-1}, 1$ day $^{-1}$ and $\infty$ (i.e., instantaneous mixing, achieved by initializing the boxes with the concentrations in the Box M (mixed) column of Table 1). For simplicity the boxes are assumed to have equal size $(\kappa=1)$.

We look first in Plate 2 at the effect of mixing on the concentrations of the hydroxyl $(\mathrm{OH})$ and hydroperoxy radicals $\left(\mathrm{HO}_{2}\right)$. $\mathrm{OH}$ in particular is an extremely important atmospheric oxidant, and if mixing can play a role in determining the $\mathrm{OH}$ abundance, this would represent a very important chemistry-mixing interaction. Such a possibility was first suggested by Bamber et al. [1984]. Indeed, we find that mixing has an

\section{TOMCAT Ozone $300 \mathrm{~K} \quad 18 \mathrm{Z} \quad \mathbf{2 8 - 0 2 - 9 5}$}

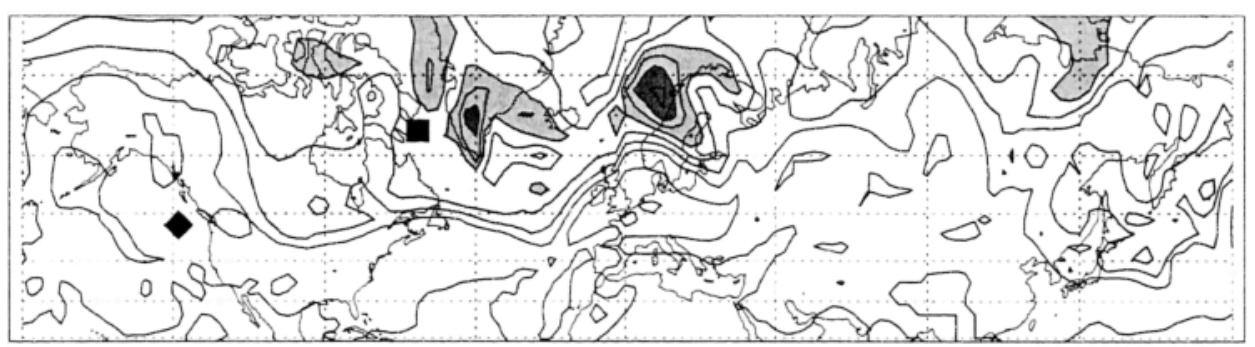

TOMCAT H2O $300 \mathrm{~K} \quad 18 \mathrm{Z} 28-02-95$

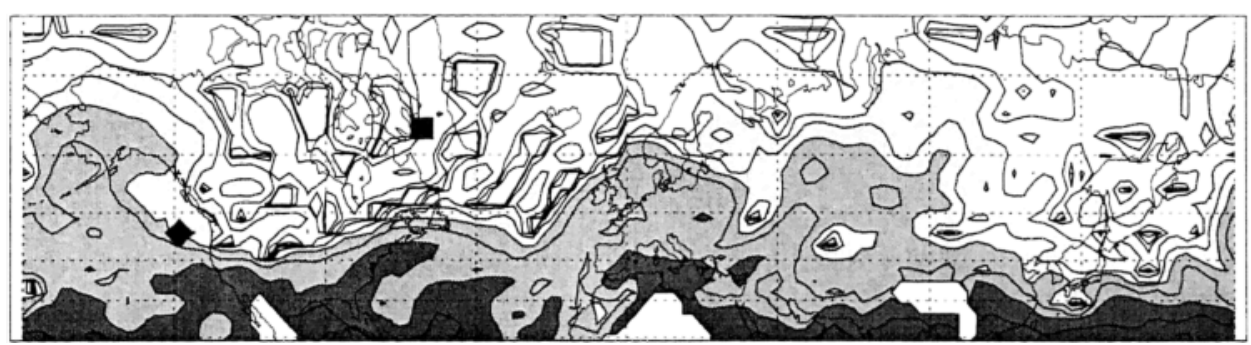

Figure 3. A contour plot showing TOMCAT ozone and $\log _{10}\left[\mathrm{H}_{2} \mathrm{O}\right]$ on the $300 \mathrm{~K}$ isentrope on the February 28,1995 . Contour intervals are $40 \mathrm{ppbv}$ in the $\mathrm{O}_{3}$ plot and 0.5 in the $\log _{10}\left[\mathrm{H}_{2} \mathrm{O}\right]$ plot, where $\mathrm{H}_{2} \mathrm{O}$ concentrations are also in ppbv. The solid square and solid diamond show the locations of the beginning of the stratospheric and tropospheric trajectories, respectively. 
important influence. For example, the instantaneous mixing case (green curve) has higher $\mathrm{OH}$ levels than either the stratospheric (red curve) or tropospheric (blue curve) unmixed boxes, and around twice the $\mathrm{OH}$ level of the average of the unmixed stratospheric / tropospheric boxes (black curve). The details of the mixing are also found to be important for the chemistry. The fastmixing ( $R=1$ day $^{-1}$ ) curve (green - long dashes) converges very rapidly from the average (black) curve to the instantaneous mixing (green) curve, while the mediummixing rate curve (green - short dashes, $R=0.2$ day $^{-1}$ ) converges more slowly from the black to the green solid curve. In the case of slow mixing (green dotted curve, $R=0.05$ day $^{-1}$ ) the $\mathrm{OH}$ levels are only beginning to converge toward the mixed case levels near the end of the 5-day integration. The mixing ratio of $\mathrm{HO}_{2}$ in the instant mixing case is slightly less than the tropospheric level but is greater than the unmixed stratospheric level and the stratosphere/troposphere average.

To understand these results, it is necessary to understand how $\mathrm{HO}_{x}\left[=\mathrm{OH}+\mathrm{HO}_{2}\right]$ levels depend on the concentrations of the other longer lived species in the boxes. As $\mathrm{HO}_{x}$ has a short lifetime in the upper tropospherelower stratosphere region, of order minutes to a few hours, it is useful to regard it as being in a photochemical steady state, with photochemical production equal to chemical loss. Several authors [Ehhalt et al., 1991; Poppe et al., 1995] have used this approach to derive steady state expressions for $\mathrm{OH}$ and $\mathrm{HO}_{2}$ in simplified chemical models. Photochemical production of $\mathrm{HO}_{x}$ occurs predominantly through the sequence

$$
\begin{aligned}
\mathrm{O}_{3}+h \nu & \rightarrow \mathrm{O}\left({ }^{1} D\right)+\mathrm{O}_{2}, \\
\mathrm{O}\left({ }^{1} D\right)+\mathrm{H}_{2} \mathrm{O} & \rightarrow 2 \mathrm{OH},
\end{aligned}
$$

as well as by $\mathrm{HO}_{2}$ production in the photolysis of formaldehyde ( $\mathrm{HCHO}$ ), acetone and higher hydrocarbon oxidation products. Loss of $\mathrm{HO}_{x}$ occurs mainly through nitric acid formation, and the self-reaction of $\mathrm{HO}_{2}$ to form hydrogen peroxide,

$$
\begin{aligned}
\mathrm{OH}+\mathrm{NO}_{2} & \rightarrow \mathrm{HNO}_{3}, \\
\mathrm{HO}_{2}+\mathrm{HO}_{2} & \rightarrow \mathrm{H}_{2} \mathrm{O}_{2}+\mathrm{O}_{2} .
\end{aligned}
$$

Total $\mathrm{HO}_{x}$ levels are controlled largely by the relative magnitude of the sources and sinks above, but the $\mathrm{OH} / \mathrm{HO}_{2}$ ratio is largely determined by the interconversion reactions, which include

$$
\begin{aligned}
\mathrm{OH}+\mathrm{CO}+\mathrm{O}_{2} & \rightarrow \mathrm{HO}_{2}+\mathrm{CO}_{2} \\
\mathrm{OH}+\mathrm{O}_{3} & \rightarrow \mathrm{HO}_{2}+\mathrm{O}_{2} \\
\mathrm{HO}_{2}+\mathrm{NO} & \rightarrow \mathrm{OH}+\mathrm{NO}_{2} \\
\mathrm{HO}_{2}+\mathrm{O}_{3} & \rightarrow \mathrm{OH}+2 \mathrm{O}_{2}
\end{aligned}
$$

(However, the relative magnitudes of the $\mathrm{HO}_{x}$ sources and sinks, including R1-R4, have a weak secondary influence on the $\mathrm{OH} / \mathrm{HO}_{2}$ ratio.) Other important, indirect, conversions from $\mathrm{OH}$ to $\mathrm{HO}_{2}$ take place when methane and higher hydrocarbons are oxidized by $\mathrm{OH}$, forming higher peroxy radicals $\mathrm{RO}_{2}$, which can lead to $\mathrm{HO}_{2}$ production in the presence of $\mathrm{O}_{3}$ or NO.

A direct consequence of mixing in the experiments is the increased production of $\mathrm{OH}$ in (R1) and (R2). It is relatively clear how mixing can increase $\mathrm{OH}$ levels through these reactions. Ozone photolysis takes place in the stratospheric air, but without mixing the

\begin{tabular}{|c|c|c|c|c|c|c|c|c|c|}
\hline \multirow[b]{2}{*}{ Species } & \multicolumn{2}{|c|}{ Box T } & \multicolumn{2}{|c|}{ Box S } & \multirow{2}{*}{$\begin{array}{r}\text { Box M } \\
\text { All Mixed }\end{array}$} & \multirow{2}{*}{$\begin{array}{r}\text { Box A } \\
\mathrm{O}_{3}, \mathrm{H}_{2} \mathrm{O} \\
\text { Mixed, Reet } \\
\text { Tropospheric }\end{array}$} & \multirow{2}{*}{$\begin{array}{r}\text { Box B } \\
\mathrm{O}_{3}, \mathrm{H}_{2} \circ \\
\text { Mixed, Rest } \\
\text { Stratospherie }\end{array}$} & \multirow{2}{*}{$\begin{array}{r}\text { Box C } \\
\mathrm{O}_{3}, \mathrm{H}_{2} \mathrm{O} \\
\text { Tropospheric } \\
\text { Rest Mixed }\end{array}$} & \multirow{2}{*}{$\begin{array}{r}\text { Box D } \\
\mathrm{O}_{3}, \mathrm{H}_{2} \mathrm{O} \\
\text { Stratospheric } \\
\text { Rest Mixed }\end{array}$} \\
\hline & $\begin{array}{l}\text { Mar. 5, } \\
1995\end{array}$ & $\begin{array}{c}\text { (Feb. 28, } \\
\text { 1995) }\end{array}$ & $\begin{array}{l}\text { Mar. 5, } \\
1995\end{array}$ & $\begin{array}{c}\text { (Feb. 2B, } \\
1995 \text { ) }\end{array}$ & & & & & \\
\hline $\mathrm{O}_{3}, \mathrm{ppbv}$ & 54.3 & $(54.7)$ & 187.0 & $(187.0)$ & 121.0 & 121.0 & 121.0 & 54.3 & 187.0 \\
\hline $\mathrm{H}_{2} \mathrm{O}$, ppmv & 875.0 & $(875.0)$ & 11.9 & (11.9) & 443.0 & 443.0 & 443.0 & 875.0 & 11.9 \\
\hline $\mathrm{CH}_{4}$, ppmv & 1.77 & $(1.77)$ & 1.73 & $(1.73)$ & 1.75 & 1.77 & 1.73 & 1.75 & 1.75 \\
\hline $\mathrm{CO}, \mathrm{ppbv}$ & 108.0 & $(109.0)$ & 82.6 & $(83.1)$ & 95.3 & 108.0 & 82.6 & 95.3 & 95.3 \\
\hline $\mathrm{NO}_{x}$, pptv & 4.8 & (11.6) & 10.4 & (29.8) & 7.6 & 4.8 & 10.4 & 7.6 & 7.6 \\
\hline $\mathrm{H}_{2} \mathrm{O}_{2}, \mathrm{pptv}$ & 379.0 & $(333.0)$ & 65.4 & $(84.6)$ & 222.0 & 379.0 & 65.4 & 222.0 & 222.0 \\
\hline HCHO, pptv & 10.4 & $(62.7)$ & 6.78 & (15.1) & 8.59 & 10.4 & 6.78 & 8.59 & 8.59 \\
\hline PAN, pptv & 44.7 & $(45.2)$ & 37.4 & $(37.6)$ & 41.1 & 44.7 & 37.4 & 41.1 & 41.1 \\
\hline $\mathrm{HNO}_{3}, \mathrm{ppbv}$ & 0.20 & $(0.21)$ & 0.54 & $(0.55)$ & 0.3 & 0.20 & 0.54 & 0.37 & 0.37 \\
\hline $\mathrm{C}_{2} \mathrm{H}_{6}, \mathrm{ppbv}$ & 2.15 & $(2.17)$ & 1.54 & (1.54) & 1.85 & 2.15 & 1.54 & 1.85 & 1.85 \\
\hline $\mathrm{C}_{3} \mathrm{H}_{8}, \mathrm{ppbv}$ & 0.52 & $(0.54)$ & 0.41 & $(0.43)$ & 0.46 & 0.52 & 0.41 & 0.46 & 0.46 \\
\hline
\end{tabular}
stratospheric air parcel has low water vapor and the excited oxygen is likely to be quenched to its ground state $\mathrm{O}\left({ }^{3} \mathrm{P}\right)$ before $\mathrm{OH}$ formation can take place in (R2). $\mathrm{Br}$ contrast, the tropospheric parcel in the absence of mixing has high water vapor but a lower level of $O\left({ }^{1} D\right)$. Mixing brings together relatively high concentrations

Table 1. The Initial Mixing Ratios for All the Experiments.

The initial mixing ratios for Boxes $\mathrm{T}$ and $\mathrm{S}$ (on March 5, 1995) are the result of box model integrations without mixing along the parcel trajectories shown in Figure 3 from February 28, 1995 to March 5, 1995. These box model integrations were initialized on February 28, 1995 with the TOMCAT concentrations at the relevant parcel positions, which are shown alongside in parentheses. Box $M$ is the mean of these stratospheric (Box S) and tropospheric (Box T) concentrations. In Boxes A and B, mean values of ozone and water vapor are combined with tropospheric and stratospheric concentrations of the remaining species, respectively. In Boxes $C$ and $D$ tropospheric and stratospheric values of ozone and water vapor, respectively, are combined with mean concentrations of the remaining species. 

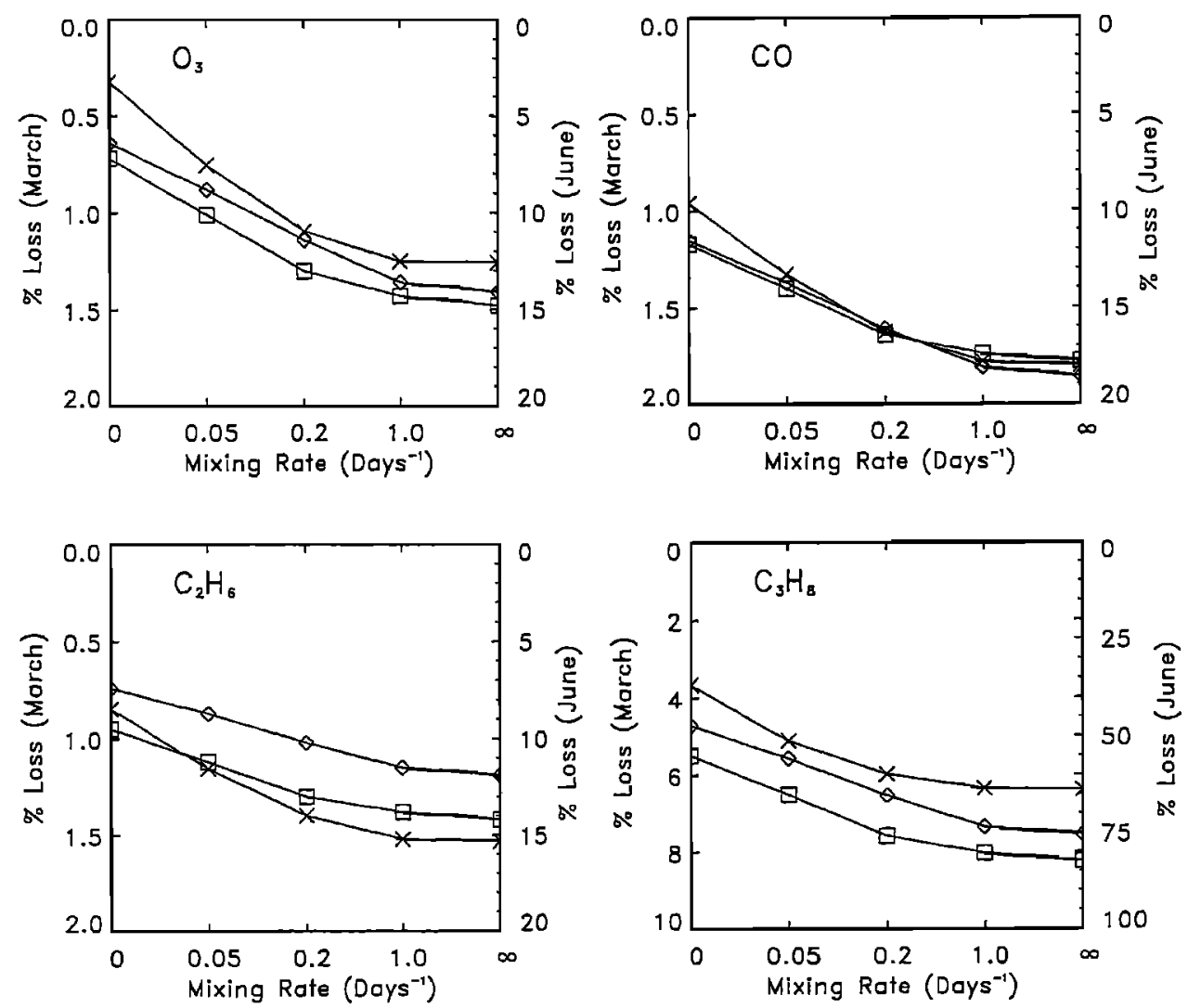

Figure 4. Showing the dependence of the total depletion of $\mathrm{O}_{3}$ and the oxidation of $\mathrm{CO}, \mathrm{C}_{2} \mathrm{H}_{6}$, and $\mathrm{C}_{3} \mathrm{H}_{8}$ on mixing rate. Results from the March 5-10 trajectory are marked as diamonds, the idealized trajectory as squares, and the June 17-22 trajectory as crosses. Note that the right-hand axis corresponds to the June case.

of $\mathrm{O}_{3}$, and hence $\mathrm{O}\left({ }^{1} \mathrm{D}\right)$, and $\mathrm{H}_{2} \mathrm{O}$ which are then able to react leading to an increase in $\mathrm{HO}_{x}$ levels.

Increasing $\mathrm{O}_{3}$ in the tropospheric box by mixing has the further effect of increasing the $\mathrm{OH} / \mathrm{HO}_{2}$ ratio by increasing $\mathrm{HO}_{2}$ conversion in (R8). This additional reaction is the reason for the nonlinear dependence of $\mathrm{OH}$ on $\mathrm{O}_{3}$ concentration (in low $\mathrm{NO}_{x}$ conditions) discussed as a limiting case by Poppe et al. [1995]. At relatively low concentrations of $\mathrm{H}_{2} \mathrm{O}$, such as those in the upper troposphere-lower stratosphere, steady state $\mathrm{OH}$ levels increase linearly with respect to $\mathrm{H}_{2} \mathrm{O}$ concentration.

In Plate $2 \mathrm{~b}, \mathrm{HO}_{2}$ levels, and also total $\mathrm{HO}_{x}$ levels, are seen to be higher in the tropospheric box than the mixed box. This is because the source of $\mathrm{HO}_{x}$ due to compounds including $\mathrm{HCHO}$ and higher hydrocarbon oxidation products is stronger in the tropospheric box. Mean $\mathrm{HO}_{2}$ levels in the boxes with finite mixing rates are again found to converge toward the levels in the instantaneous mixing case.

Increased levels of $\mathrm{OH}$ naturally mean increased oxidation rates for a large number of species, notably methane, $\mathrm{CO}$ and higher hydrocarbons. Species associated with methane oxidation $\left(\mathrm{CH}_{3} \mathrm{O}_{2}, \mathrm{CH}_{3} \mathrm{NO}_{3}, \mathrm{CH}_{3} \mathrm{O}\right.$, $\mathrm{HCHO}, \mathrm{CH}_{3} \mathrm{OOH}, \mathrm{CH}_{3} \mathrm{OH}, \mathrm{CH}_{3} \mathrm{O}_{2} \mathrm{NO}_{2}$ ) all increase when the mixing rate increases, consistent with this description. In the low $\mathrm{NO}_{x}$ conditions of the control run,
$\mathrm{O}_{3}$ concentrations decrease over the length of the trajectory calculations. Figure 4 shows how the total decline in $\mathrm{O}_{3}$ and the oxidation of $\mathrm{CO}, \mathrm{C}_{2} \mathrm{H}_{6}$ and $\mathrm{C}_{3} \mathrm{H}_{8}$ over the 5 days, given as percentage total loss, are affected by mixing rate along the trajectories considered above (curves with diamonds). The total decrease of each species is increased by around a factor of 2 between zero and instantaneous mixing. The amount of $\mathrm{O}_{3}$ loss is particularly sensitive to the mixing rate, as it is lost due to reaction with both the hydroperoxy radical $\mathrm{HO}_{2}$ in (R8) and by destruction by photolysis in (R1), leading to $\mathrm{OH}$ production. By contrast, in the higher $\mathrm{NO}_{x}$ conditions discussed below, the oxidation of NO to $\mathrm{NO}_{2}$ by $\mathrm{HO}_{2}$ in (R7), and the subsequent photolysis of $\mathrm{NO}_{2}$ leads to $\mathrm{O}_{3}$ production.

Figure 5 shows the effect of mixing rate on the evolution of $\mathrm{NO}_{x}\left[=\mathrm{NO}+\mathrm{NO}_{2}\right]$ concentrations (averaged between the two boxes). The concentrations of $\mathrm{NO}_{x}$ taken from TOMCAT for this experiment are arguably fairly low, but even at these levels of $\mathrm{NO}_{x},(\mathrm{R} 7)$ is important in the $\mathrm{HO}_{x}$ budget. The total reduction of $\mathrm{NO}_{x}$ is found to increase with mixing rate, because higher average $\mathrm{OH}$ levels lead to increased nitric acid formation in (R3). The same sensitivity of $\mathrm{NO}_{x}$ loss to mixing was also found in the higher $\mathrm{NO}_{x}$ calculations described in section 4.4 . 


\subsection{Sensitivity to Trajectory Details}

To verify that the above results are independent of details of the trajectory chosen, and are also independent of the photolysis conditions associated with the season (early March for the case above), we have carried out variations on the experiment described in section 4.1. First, instead of an actual calculated trajectory we have chosen an idealized, fixed trajectory at pressure $400 \mathrm{mb}$, . temperature $245 \mathrm{~K}$, latitude $51^{\circ} \mathrm{N}$ and longitude $0^{\circ}$, running from March 5 to 10 as above. Second, the trajectory procedure described above was repeated for a STE event observed during the TOASTE-C project from June 16 to 26, 1996 [Gouget et al., 2000], when an initialization based on June TOMCAT chemical concentrations was also used. $\mathrm{HO}_{x}$ levels along both of these trajectories (not shown for June case, see Plate 3 for idealized case) were found to have the same qualitative dependence on mixing rate as the experiments described in section 4.1 .

Figure 4 also shows the dependence of $\mathrm{O}_{3}, \mathrm{CO}, \mathrm{C}_{2} \mathrm{H}_{6}$, and $\mathrm{C}_{3} \mathrm{H}_{8}$ decline on the mixing rate between the boxes for these experiments. The idealized trajectory results are plotted as squares, and the June 1996 results are plotted as crosses. The chemical loss of each species in June is found to be around 10 times that in the March cases, due to increased photolysis rates. However, the qualitative dependence on mixing rate is otherwise almost exactly as described above.

\subsection{Sensitivity to Constituents Mixed}

To test the hypothesis that it is mixing between water vapor and ozone alone that is significant in setting the $\mathrm{HO}_{x}$ levels in the above experiments, we performed further tests. The box model (without mixing) was integrated along the idealized trajectory with the initial concentrations set in turn to those described as Boxes $\mathrm{A}, \mathrm{B}, \mathrm{C}$, and D shown in Table 1. In Boxes $\mathrm{A}$ and $\mathrm{B}, \mathrm{O}_{3}$ and $\mathrm{H}_{2} \mathrm{O}$ are at "mixed" concentrations, and the other concentrations are tropospheric and stratospheric, respectively. In Boxes $\mathrm{C}$ and $\mathrm{D}$ the other chemical species are mixed, and $\mathrm{O}_{3}$ and $\mathrm{H}_{2} \mathrm{O}$ have tropospheric concentrations (Box $\mathrm{C}$ ) and stratospheric concentrations (Box D), respectively. If $\mathrm{HO}_{x}$ levels are determined by $\mathrm{O}_{3}$ and $\mathrm{H}_{2} \mathrm{O}$ concentrations alone in our experiments, then Boxes $\mathrm{A}$ and $\mathrm{B}$ should have $\mathrm{HO}_{x}$ levels comparable with Box M, Box C with Box T, and Box D with Box S. Plate 3 shows the results of these runs, and this is largely what is found. It is notable that Box D has considerably higher $\mathrm{HO}_{x}$ levels compared with Box S, as alternative sources of $\mathrm{HO}_{x}$ are available due to the higher hydrocarbon and $\mathrm{HCHO}$ concentrations.

These results do not mean that $\mathrm{HO}_{x}$ levels are insensitive to the concentrations of species other than water vapor and ozone. It means instead that the contrasts across the tropopause of the other species are not suffciently strong at this level for mixing between them to have a great effect on $\mathrm{HO}_{x}$ levels. Nonisentropic STE

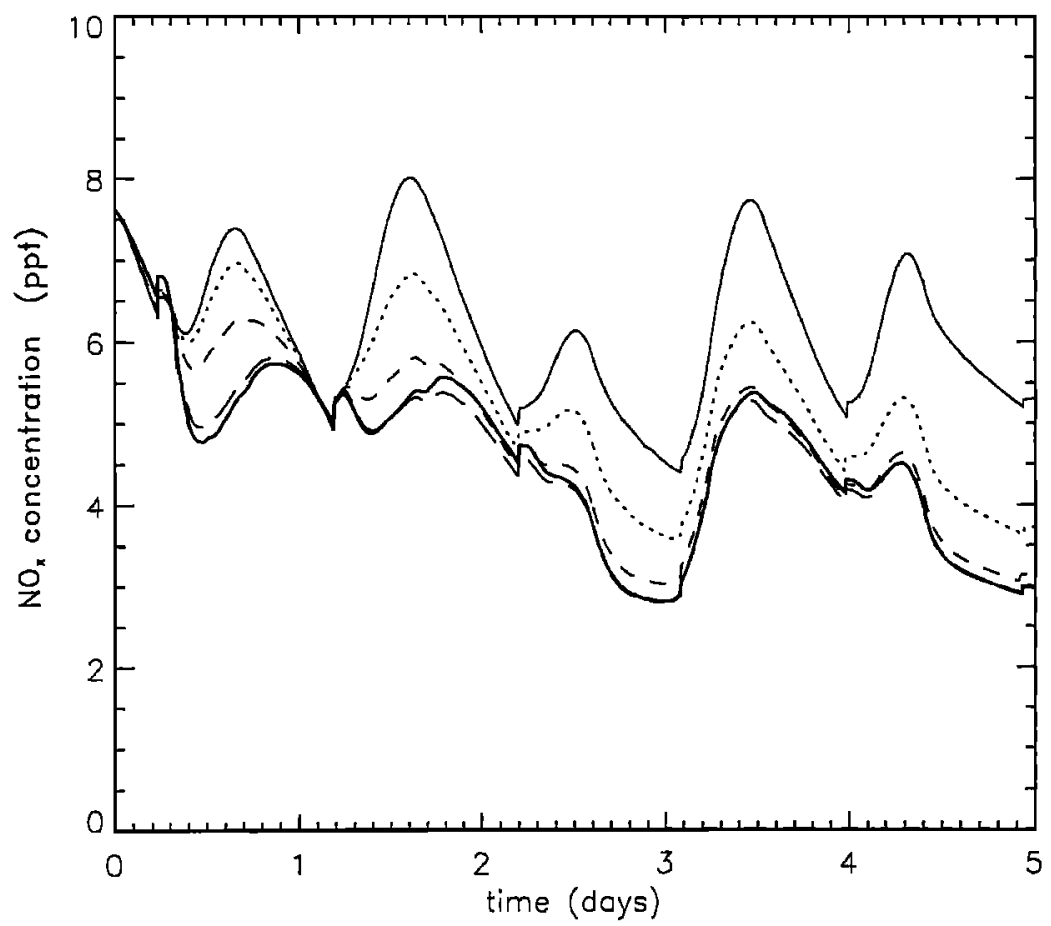

Figure 5. Curves showing the evolution of total $\mathrm{NO}_{x}$ in the boxes, in the experiments with different mixing rates. The light solid curve shows average $\mathrm{NO}_{x}$ in the boxes in the case with no mixing, the dotted curve that with $R=0.05$ day $^{-1}$, short dashes $R=0.2$ day $^{-1}$, long dashes $R=1$ day $^{-1}$, and the thick solid curve the instantaneous mixing case. 
events, such as mixing through deep convection, have the potential to bring together air parcels with more widely differing concentrations of hydrocarbons, $\mathrm{CO}$, and $\mathrm{NO}_{x}$. The special case of $\mathrm{NO}_{x}$ is discussed next.

\subsection{Sensitivity to $\mathrm{NO}_{x}$ Levels}

Up to this point we have considered the mixing of stratospheric air and relatively unpolluted upper tropospheric air with low- $\mathrm{NO}_{x}$ concentrations. However, observations [Brunner et al., 1998] indicate that large plumes of high- $\mathrm{NO}_{x}(\approx 0.5 \mathrm{ppbv})$ air are observable intermittently in the middle troposphere on certain isentropic levels. In addition, the initial $\mathrm{NO}_{x}$ levels in boxes $T$ and $S$ are arguably rather low for the upper troposphere-lower stratosphere region [Hauglustaine et al., 1996], because photochemical models including TOMCAT typically underestimate $\mathrm{NO}_{x}$ levels in this region. To test the sensitivity of the box model behavior to $\mathrm{NO}_{x}$ levels, further experiments were performed along the idealized trajectory with initial conditions set to those in Box T, apart from the $\mathrm{NO}_{x}$ levels which were set to 10 times (Box $T^{*}-48$ parts per trillion by volume (pptv) $\mathrm{NO}_{x}$ ) and 100 times (Box $\mathrm{T}^{* *}-480$ pptv $\mathrm{NO}_{x}$ ) those in Box T, respectively. Experiments with Box $\mathrm{M}^{*}$ (as Box M but with 29.2 pptv $\mathrm{NO}_{x}$ ) and Box $\mathrm{M}^{* *}(245$ pptv $\mathrm{NO}_{x}$ ) were also performed to test the sensitivity to instantaneous mixing between Box $\mathrm{T}^{*}$ and Box $\mathrm{S}$ as well as Box $\mathrm{T}^{* *}$ and Box $\mathrm{S}$ respectively. The resulting $\mathrm{HO}_{x}$ levels for these experiments are shown in Plate 4.

Comparing the $10 \times \mathrm{NO}_{x}$ experiments (dashed curves) and the control experiments (solid curves), $\mathrm{OH}$ levels are enhanced in each box in the former, and this can be explained by an increase in the ratio of $\mathrm{OH}$ to $\mathrm{HO}_{2}$ due to enhanced conversion in (R7). By contrast, $\mathrm{HO}_{2}$ levels (and total $\mathrm{HO}_{x}$ levels) are close to unchanged. The qualitative sensitivity to mixing in this case is unchanged, and Box $\mathrm{M}^{*}$ has around $5 \%$ higher $\mathrm{OH}$ than Box T*, and around 3 times that of Box S. At this level of $\mathrm{NO}_{x}$ it is notable that ozone production due to the oxidation of $\mathrm{NO}$ in (R7) and subsequent photolysis of $\mathrm{NO}_{2}$ dominates over loss in (R1) and (R8).

The situation in the case of the $100 \times \mathrm{NO}_{x}$ experiments (dotted curves) is somewhat different. As $\mathrm{NO}_{x}$ increases, the sink of $\mathrm{HO}_{x}$ in (R3) becomes more important than that in (R4), and $\mathrm{HO}_{x}$ levels become inversely proportional to $\mathrm{NO}_{x}$ levels [Poppe et al., 1995]. However, the $\mathrm{OH} / \mathrm{HO}_{2}$ ratio is further increased due to the greater importance of (R7), and Box $\mathrm{T}^{* *}$ has higher $\mathrm{OH}$ compared with Box T*, despite having lower total $\mathrm{HO}_{x}$. Nighttime $\mathrm{HO}_{2}$ levels are significant in Box $\mathrm{T}^{* *}$ (over 1
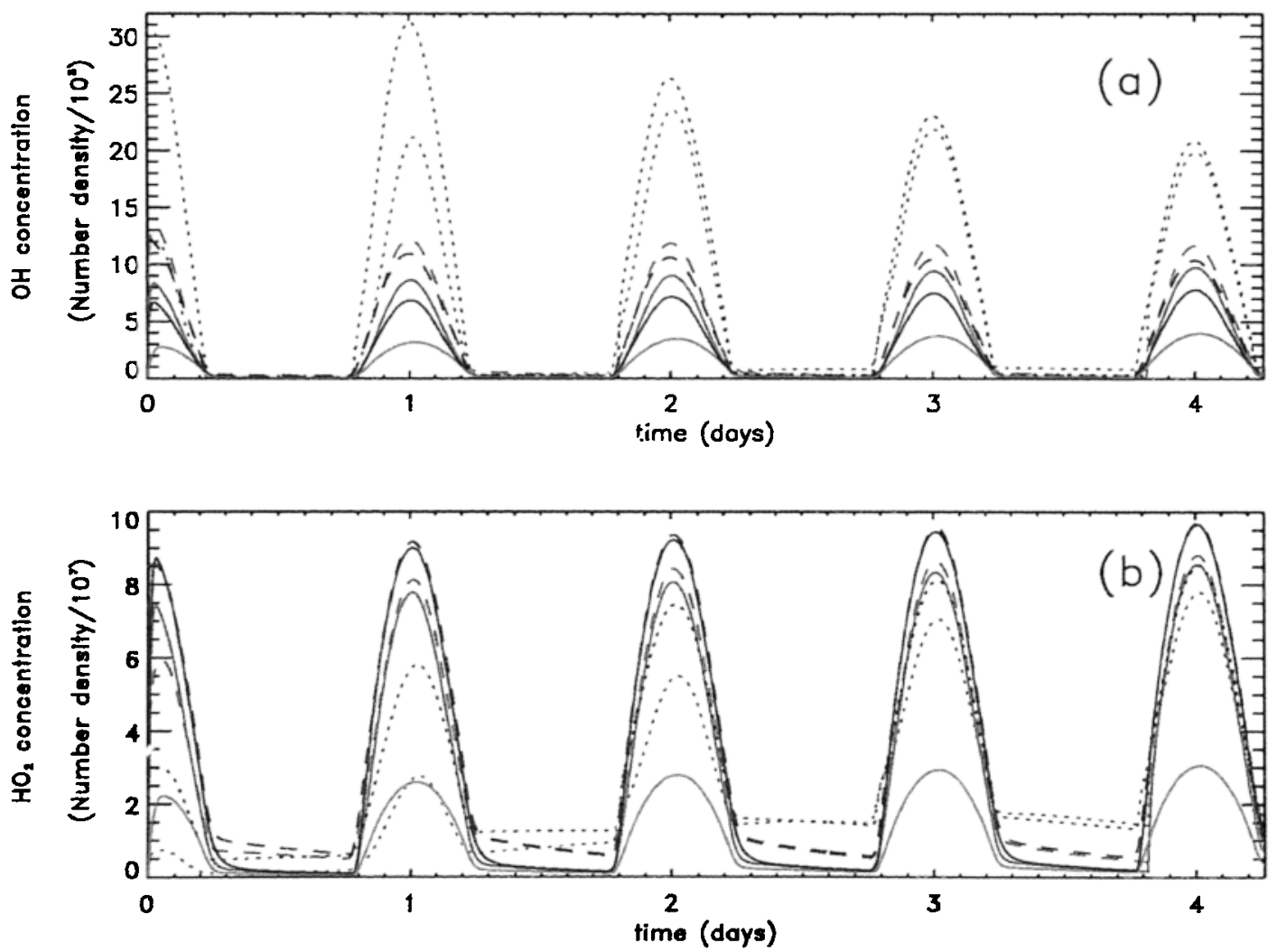

Plate 4. As Plate 2, but showing concentrations in the enhanced $\mathrm{NO}_{x}$ experiments (calculations along the idealized trajectory). Solid curves show standard $\mathrm{NO}_{x}$ levels (blue curve, Box $\mathrm{T}$; red curve, Box S; green curve, Box M). Dashed curves indicate experiments with $10 \times$ tropospheric $\mathrm{NO}_{x}$ levels (blue curve, Box T*; green curve, Box $\mathrm{M}^{*}$ ), dotted curves indicate $100 \times$ tropospheric $\mathrm{NO}_{x}$ levels (blue curve, Box $\mathrm{T}^{* *}$; green curve, Box $\mathrm{M}^{* *}$ ). 
$\times 10^{7} \mathrm{~mole} / \mathrm{cm}^{3}$ ), with the largest source in our model due to the breakdown of $\mathrm{HO}_{2} \mathrm{NO}_{2}$.

When Box $\mathrm{T}^{* *}$ is mixed with Box $\mathrm{S}$, the reduction in $\mathrm{OH}$ levels due to the dilution of the $\mathrm{NO}_{x}$ present in Box $\mathrm{T}^{* *}$ dominates over the additional source of $\mathrm{HO}_{x}$ in (R1)-(R2) due to mixing of $\mathrm{O}_{3}$ and $\mathrm{H}_{2} \mathrm{O}$. This results in Box $\mathrm{M}^{* *}$ having lower $\mathrm{OH}$ concentrations compared with Box $\mathrm{T}^{* *}$. Clearly, once tropospheric $\mathrm{NO}_{x}$ concentrations reach the order of 0.5 ppbv as in this ease, then mixing of $\mathrm{NO}_{x}$ becomes more important in controlling the chemistry during an STE event.

\section{Summary and Conclusions}

In this paper we have considered the chemical consequences of mixing stratospheric and tropospheric air. Substantial contrasts in mixing ratios of both ozone and water vapor across the tropopause on the 300 $340 \mathrm{~K}$ isentropic surfaces were identified in the TOMCAT chemical transport model. Quasi-isentropic, crosstropopause stirring at these levels can therefore bring air parcels with substantially different chemical properties together. Above $340 \mathrm{~K}$ the saturation mixing ratio in the tropical upper troposphere is sufficiently low, due to the cold temperatures in this region, that the crosstropopause gradient in water vapor is much reduced.
Isentropic surfaces close to $300 \mathrm{~K}$, by contrast, tend to have a high cross-tropopause gradient in water vapor but a lower gradient in ozone. Isentropic surfaces much below $300 \mathrm{~K}$ do not cross the tropopause at all.

A stratosphere-troposphere exchange event from the March 5, 1995 was used as a case study of the stirring of a stratospheric intrusion into the troposphere. Back trajectories were used in conjunction with chemical constituent concentrations calculated in TOMCAT in order to establish the chemical contrasts between typical air parcels in the intrusion and the background air before the onset of mixing. Idealized two-box model experiments were then used to test the sensitivity of the chemical evolution of the stratospheric and tropospheric air parcels to mixing between them. The main conclusion is that mixed air with intermediate $\mathrm{H}_{2} \mathrm{O}$ and $\mathrm{O}_{3}$ concentrations generate higher concentrations of the shortlived hydroxyl $(\mathrm{OH})$ radical than either tropospheric or stratospheric air alone, a possibility first suggested by Bamber et al. [1984]. This result was shown to be independent of details of the season or trajectory chosen, and it was confirmed that it was the mixing of $\mathrm{O}_{3}$ and $\mathrm{H}_{2} \mathrm{O}$, rather than any other species, that was most important in generating the enhanced $\mathrm{OH}$ levels.

This picture is summarized in Figure 6. This shows peak daily $\mathrm{OH}$ concentrations calculated as a function

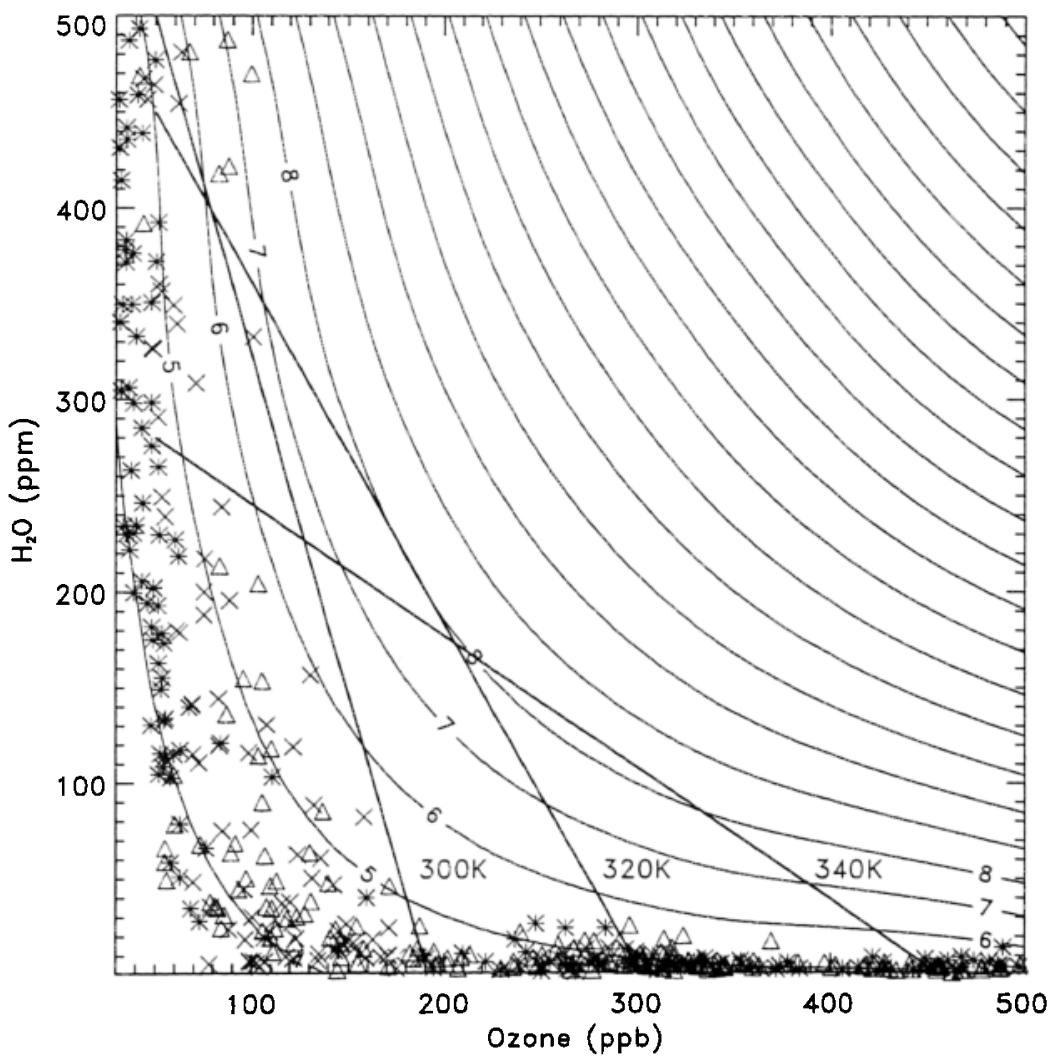

Figure 6. Contour plot of peak daily $\mathrm{OH}$ levels calculated as a function of $\mathrm{O}_{3}$ and $\mathrm{H}_{2} \mathrm{O}$ from a series of box model calculations. All other concentrations are as in Box $\mathrm{M}$, and physical parameters are as for the idealized trajectory. The contour interval is $1 \times 10^{5}$ (number density). See text for details of points plotted and mixing lines. 
of $\mathrm{O}_{3}$ and $\mathrm{H}_{2} \mathrm{O}$ concentrations. The $\mathrm{OH}$ concentrations are derived from a series of box model calculations with $\mathrm{O}_{3}$ and $\mathrm{H}_{2} \mathrm{O}$ concentrations imposed as initial values. All other chemical concentrations are initially set equal to those in Box M. Physical conditions are as for the idealized trajectory, and each integration is run forward from sunrise for 12 hours. Superimposed on this plot are instantaneous concentrations of $\mathrm{O}_{3}$ and $\mathrm{H}_{2} \mathrm{O}$ taken from TOMCAT on March 5, 1995. Triangles denote concentrations on the $300 \mathrm{~K}$ surface, crosses on the $320 \mathrm{~K}$ surface and stars on the $340 \mathrm{~K}$ surface. The instantaneous samples from TOMCAT are clearly divided into tropospheric (low $\mathrm{O}_{3}$, high $\mathrm{H}_{2} \mathrm{O}$ ) and stratospheric (high $\mathrm{O}_{3}$, low $\mathrm{H}_{2} \mathrm{O}$ ). Also plotted on the diagram are examples of "mixing lines" [e.g., Plumb and $K o$, 1992] showing the $\mathrm{O}_{3}$ and $\mathrm{H}_{2} \mathrm{O}$ concentrations attainable as typical stratospheric and tropospheric parcels are mixed rapidly, that is, on timescales much shorter than the chemical timescales of these species. Rapid mixing between air parcels corresponding to separate points in this diagram leads to concentrations that lie on the straight lines connecting them. The mixing lines indicate this. The contours give an approximate picture of the enhanced $\mathrm{OH}$ concentrations attainable in mixed air parcels lying along the straight lines. At levels higher than the $340 \mathrm{~K}$ surface, the contrast between tropospheric and stratospheric $\mathrm{H}_{2} \mathrm{O}$ concentrations was found to be sufficiently low that mixing does not lead to enhanced $\mathrm{OH}$ concentrations. In Figure 6, a typical mixing line for the $350 \mathrm{~K}$ surface or higher would lie close to the $x$-axis. At these higher levels, alternative sources of $\mathrm{HO}_{x}$, such as the photolysis of formaldehyde and acetone, are more important than the source from $\mathrm{O}_{3}$ and $\mathrm{H}_{2} \mathrm{O}$. The sensitivity of the chemistry to mixing will depend on the existence of cross-tropopause gradients of either $\mathrm{HCHO}$, acetone, or $\mathrm{NO}_{x}$ as well as $\mathrm{O}_{3}$, rather than $\mathrm{H}_{2} \mathrm{O}$. (The photolysis of acetone $\left(\mathrm{CH}_{3}\right)_{2} \mathrm{CO}$, which has been recently shown to have an important role as a source of $\mathrm{HO}_{2}$ in dry conditions [e.g., Wennberg et al., 1998], is neglected in our chemistry scheme.) These regimes will be explored in future work.

Our results suggest that the importance of the mixing rate between stratospheric and tropospheric air is in setting the timescale on which the enhanced $\mathrm{OH}$ levels are attained. This in turn determines the rate of oxidation of $\mathrm{CO}$, hydrocarbons and the rate of change of $\mathrm{O}_{3}$. It may also affect halogenated hydrocarbons such as $\mathrm{CHBr}_{3}$ and $\mathrm{CH}_{2} \mathrm{Br}_{2}$, which are also oxidized by $\mathrm{OH}$. These have been recently shown [Dvortsov et al., 1999] to have a potentially important role in midlatitude, lower stratospheric $\mathrm{O}_{3}$ depletion.

An important issue not explored here is the question of how long a typical air parcel traveling between stratosphere and troposphere actually remains in a "mixed" state, i.e. with $\mathrm{O}_{3}$ and $\mathrm{H}_{2} \mathrm{O}$ concentrations intermediate between tropospheric and stratospheric, before being diluted to background levels. This timescale is impor- tant, as while the parcel is in a mixed state, the chemistry associated with enhanced $\mathrm{OH}$ concentrations will have an impact on the chemical species transported in the parcel. This question cannot be answered by global chemical transport models alone, as implicit or explicit artificial diffusion associated with finite numerical resolution is likely to dilute such a parcel much too quickly. It is difficult to assess the global impact of the anomalous chemistry associated with "mixed" air that we have described here without a more thorough understanding of the dilution of air parcels involved in STE events.

The case study investigated here involved mixing of stratospheric air and unpolluted upper troposphere air with relatively low $\mathrm{NO}_{x}$ concentrations. Experiments to test the sensitivity to tropospheric $\mathrm{NO}_{x}$ levels were performed to test the range of validity of our results. Our results (Plate 4a), as well as those of others [Kley, 1997], indicate that at elevated concentrations of $\mathrm{NO}_{x}$, $\mathrm{OH}$ levels are controlled by the amount of $\mathrm{NO}_{x}$, rather than $\mathrm{O}_{3}$ and $\mathrm{H}_{2} \mathrm{O}$. Sources of high- $\mathrm{NO}_{x}$ concentrations include lightning and aircraft emissions, as well as transport from the polluted boundary layer. The high$\mathrm{NO}_{x}$ plumes noted by Brunner et al. [1998] may arise from such transport due to frontal conveyor belts. A priority of future work is to investigate the sensitivity of the chemistry in such frontal conveyor belts to the dilution of $\mathrm{NO}_{x}$-rich air, including the effects of other pollutants such as hydrocarbons and enhanced $\mathrm{CO}$.

Acknowledgments. This research was supported by the European Commission through the TOASTE-C project (contract ENV4-CT95-0057). Data and computing resources for the trajectory calculations were provided by the British Atmospheric Data Centre and the U.K. Universities Global Atmospheric Modelling Programme, both funded by the Natural Environmental Research Council. The Cambridge Centre for Atmospheric Science receives funding from the Isaac Newton Trust. The chemistry scheme used data from the Master Chemical Mechanism developed by School of Chemistry, University of Leeds, England. D.G.H.T. would like to thank Martyn Chipperfield, David Lary, and Dudley Shallcross for discussions on chemistry and mixing.

\section{References}

Ancellet, G., M. Beckmann, and A. Papayannis, Impact of a cut-off low development on downward transport of ozone in the troposphere, J. Geophys. Res., 99, 3451-3468, 1994.

Ancellet, G., R. Wilson, A. K. Marsh, and G. Vaughan, Transport of ozone and stratosphere-troposphere exchange-B (TOASTE-B), final report, chap. 3, Comm. of Eur. Communities Environ. Res. Program, European Commission, Brussels, Belgium, 1996.

Appenzeller, C., and H. C. Davies, Structure of stratospheric intrusions into the troposphere, Nature, 358, 570-572, 1992.

Appenzeller, C., H. C. Davies, and W. A. Norton, Fragmentation of stratospheric intrusions, J. Geophys. Res., 101, 1435-1456, 1996.

Bamber, D. J., P. G. W. Healey, B. M. R. Jones, S. A. Penkett, A. F. Tuck, and G. Vaughan, Vertical profiles of tropospheric gases: Chemical consequences of stratospheric intrusions, Atmos. Environ., 18, 1759-1766, 1984. 
Bithell, M., and L. J. Gray, Contour lengthening rates near the tropopause, Geophys. Res. Lett., 24, 2721-2724, 1997.

Brunner, D., J. Staehelin, and D. Jeker, Large-scale nitrogen oxide plumes in the tropopause region and implications for ozone, Science, 282, 1305-1309, 1998.

Butchart, N., and E. E. Remsberg, Area of the stratospheric polar vortex as a diagnostic for tracer transport on an isentropic surface, J. Atmos. Sci., 43, 3013-3031, 1986.

Chen, P., Isentropic cross-tropopause mass exchange in the extratropics, J. Geophys. Res., 100, 16,661-16,673, 1995.

Dvorstov, V. L., M. A. Geller, S. Solomon, S. M. Schauffler, E. L. Atlas, and D. R. Blake, Rethinking reactive halogen budgets in the midlatitude lower stratosphere, Geophys. Res. Lett., 26, 1699-1702, 1999.

Ehhalt, D. H., Atmospheric chemistry: Radical ideas, Science, 279, 1002-1003, 1998.

Ehhalt, D. H., H. P. Dorn, and D. Poppe, The chemistry of the hydroxyl radical in the troposphere, Proc. $R$. Soc. Edinburgh, Ser. B, 97, 17-34, 1991.

Eluskiewicz, J., A three-dimensional view of the stratosphere-troposphere exchange in the GFDL SKYHI model, Geophys. Res. Lett., 23, 2489-2493, 1996.

Evans, M. J., et al., Evaluation of a Lagrangian box model using field measurements from EASE (Eastern Atlantic Summer Experiment) 1996, Atmos. Environ., 34, 3843$3863,2000$.

Gouget, H., G. Vaughan, A. Marenco, and H. G. J. Smit, Decay of a cut-off low and contribution to stratospheretroposphere exchange, Q. J.R. Meteorol. Soc., 126, 1117$1142,2000$.

Hauglustaine, D. A., B. A. Ridley, S. Solomon, P. G. Hess, and S. Madronich, $\mathrm{HNO}_{3} / \mathrm{NO}_{x}$ ratio in the remote troposphere during MLOPEX 2: Evidence for nitric acid reduction on carbonaceous aerosol, Geophys. Res. Lett., 23, 2609-2612, 1996.

Haynes, P. H., and J. Anglade, The vertical-scale cascade in atmospheric tracers due to large-scale differential advection, J. Atmos. Sci., 54, 1121-1136, 1997.

Haynes, P. H., and E. F. Shuckburgh, Effective diffusivity as a diagnostic of atmospheric transport, II, Troposphere and lower stratosphere, $J$. Geophys. Res., 105, 22,795$22,810,2000$.

Holton, J. R., P. H. Haynes, M. E. McIntyre, A. R. Douglass, R. B. Rood, and L. Pfister, Stratosphere-troposphere exchange, Rev. Geophys., 33, 403-439, 1995.

Kley, D., Tropospheric chemistry and transport, Science, 276, 1043-1045, 1997.

Law, K. S., P. H. Plantevin, D. E. Shallcross, H. L. Rogers, J. A. Pyle, C. Grouhel, V. Thouret, and A. Marenco, Evaluation of modeled $\mathrm{O}_{3}$ using Measurement of Ozone by Airbus In-Service Aircraft (MOZAIC) data, J. Geophys. Res., 103, 25,721-25,737, 1998.

Law, K. S., P. H. Plantevin, V. Thouret, A. Marenco, W. A. H. Asman, M. Lawrence, P. J. Crutzen, J.-F. Muller, D. A. Hauglustaine, and M. Kanakidou, Comparison between global chemistry transport model results and Measurement of Ozone by Airbus In-Service Aircraft (MOZAIC) data, J. Geophys. Res., 105, 1503-1525, 2000.

Mahlman, J. D., Dynamics of transport processes in the upper troposphere, Science, 276, 1079-1083, 1997.

McIntyre, M. E., Atmospheric dynamics: Some fundamentals, with observational implications, in The Use of EOS for Studies of Atmospheric Physics, edited by J. C. Gille and G. Visconti, pp. 313-386, North-Holland, New York, 1992.
Methven, J., Ofline trajectories: Calculation and accuracy. UGAMP Tech. Rep. 44, Dep. of Meteorol., Univ. of Reading, England, 1997.

Peters, D., and D. W. Waugh, Influence of barotropic shear on the poleward advection of upper tropospheric air, $J$. Atmos. Sci., 53, 3013-3031, 1996.

Plumb, R. A., and M. K. W. Ko, Interrelationships between mixing ratios of long-lived stratospheric constituents, $J$. Geophys. Res., 97, 10,145-10,156, 1992.

Poppe, D., J. Zimmermann, and H. P. Dorn, Field data and model calculations for the hydroxyl radical, J. Atmos. Sci., 52, 3402-3407, 1995.

Price, J. D., and G. Vaughan, The potential for stratosphere-troposphere exchange in cut-off-low systems, Q. J. R. Meteorol. Soc., 119, 343-365, 1993.

Stockwell, D. Z., and M. P. Chipperfield, A tropospheric chemical transport model: Development and validation of the model transport schemes, $Q$. J. R. Meteorol. Soc., 125, 1747-1783, 1999.

Sutton, R., H. Maclean, R. Swinbank, A. O'Neill, and F. W. Taylor, High resolution tracer fields estimated from satellite observations using Lagrangian trajectory calculations, J. Atmos. Sci., 51, 2995-3005, 1994.

Tan, D. G. H., P. H. Haynes, A. R. MacKenzie, and J. A. Pyle, Effects of fluid-dynamical stirring and mixing on the deactivation of stratospheric chlorine, J. Geophys. Res., 103, 1585-1605, 1998.

Thorncroft, C. D., B. J. Hoskins and M. E. MeIntyre, Two paradigms of baroclinic life cycle behaviour. Q. J. R. Meteorol. Soc., 119, 17-35, 1993.

Thuburn, J. and D. G. H. Tan, A parameterization for mixdown time of atmospheric chemicals, J. Geophys. Res., 102, 13,037-13,049, 1997.

Vaughan, G., and C. Timmis, Transport of near-tropopause air into the lower midlatitude stratosphere, $Q$. J. $R$. Meteorol. Soc., 124, 1559-1578, 1998.

Wennberg, P. O. et al., Hydrogen radicals, nitrogen radicals, and the production of $\mathrm{O}_{3}$ in the upper troposphere, Science, 279, 49-53, 1998.

Wild, O., K. S. Law, D. S. McKenna, B. J. Bandy, S. A. Penkett, and J. A. Pyle, Photochemical trajectory modeling studies of the North Atlantic region during August 1993, J. Geophys. Res., 101, 29,269-29,288, 1996.

J. G. Esler, Department of Mathematics, University College London, Gower Street, London, WC1E 6BT, England. (gavin@math.ucl.ac.uk)

M. J. Evans, Pierce Hall, 29 Oxford St., Harvard University, Cambridge, MA 02138. (mje@io.harvard.edu)

P. H. Haynes, Department of Applied Mathematics and Theoretical Physics, Centre for Atmospheric Science, University of Cambridge, Silver Street, Cambridge, CB3 9EW, England. (P.H.Haynes@damtp.cam.ac.uk)

K. S. Law, P. H. Plantevin, and J. A. Pyle, Department of Chemistry, Centre for Atmospheric Science, University of Cambridge, Lensfield Road, Cambridge, CB2 1EW, England. (kathy.law@atm.ch.cam.ac.uk; pyle@atm.ch.cam.ac.uk)

D. G. H. Tan, The Hadley Centre, Meteorological Office, London Road, Bracknell, Berkshire, RG12 2SZ, England. (dtan@meto.gov.uk)

(Received May 8, 2000; revised June 28, 2000; accepted July 3, 2000.) 